\title{
Tick-borne Diseases (Borreliosis, Anaplasmosis, Babesiosis) in German and Austrian Dogs: Status quo and Review of Distribution, Transmission, Clinical Findings, Diagnostics and Prophylaxis
}

Nikola Pantchev' $\bowtie$, Silvia Pluta', Elke Huisinga', Stephanie Nather',

Miriam Scheufelen', Majda Globokar Vrhovec' ', Andrea Schweinitz', Herwig Hampel2, Reinhard K. Straubinger ${ }^{3}$

1 IDEXX Laboratories, 71636 Ludwigsburg, Germany

2 IDEXX Laboratories, 1010 Vienna, Austria

${ }^{3}$ Bacteriology and Mycology, Institute for Infectious Diseases and Zoonoses, Department of Veterinary Sciences, LMU Munich, 80539 Munich, Germany

Corresponding author:

\section{Nikola Pantchev}

$\triangle$ E-mail: nikola-pantchev@idexx.com

\section{Abstract}

Tick-borne diseases (TBD) in dogs have gained in significance in German and Austrian veterinary practices. The widespread European tick species Ixodes ricinus represents an important vector for spirochaetes of the Borrelia burgdorferi sensu lato group and Rickettsiales such as Anaplasma phagocytophilum. The meadow or ornate dog tick (Dermacentor reticulatus) is an important vector for Babesia canis, as is the brown dog tick (Rhipicephalus sanguineus) for Babesia vogeli in the Mediterranean region. The present work covers pathogen transmission by tick vectors, including the mechanisms and the minimum intervals required, in conjunction with possible non-vector-borne transmission routes. It also addresses the incubation periods, pathogenicity and clinical findings associated with each pathogen and genospecies and presents case examples. Current data on prevalence, annual fluctuations and distribution in various pre-selected dog populations (symptomatic versus asymptomatic) in both countries are depicted in maps. Reasons for changes in prevalence (especially of Borrelia) are discussed. Criteria and algorithms for clinical diagnosis and monitoring in dogs, including case history, direct detection (blood smears, molecular detection by species-specific PCR and sequencing) and indirect methods (whole-cell and peptide-based antibody tests), are presented, together with laboratory abnormalities (haematology, clinical chemistry, urine). The role 
of anti-C6 antibody concentration (ACAC) and its correlation with proteinuria and Lyme nephritis are assessed on the basis of new data. Consideration is also given to the importance of blood smears, PCR and serology in the case of anaplasmosis and babesiosis, and the diagnostic value of combining these methods. The relevance of molecular differentiation of Anaplasma species (A.phagocytophilum versus A.platys) and Babesia spp. (large versus small forms) in cases of serological crossreaction is emphasized. A summary is given of methods for prophylaxis using acaricide products (collars, spot-on solutions and oral treatments in both countries), vaccination (Borrelia and Babesia vaccines) and imidocarb-based chemoprophylaxis for large Babesia.

\section{Introduction}

Tick-borne diseases (TBD) in dogs have gained in significance in German and Austrian veterinary practices. The widespread European tick species Ixodes ricinus is a major vector of spirochaetes from the Borrelia burgdorferi sensu lato complex (Bbsl) and Rickettsiales such as Anaplasma phagocytophilum. The meadow or ornate dog tick (Dermacentor reticulatus) is an important vector for Babesia canis, as is the brown dog tick (Rhipicephalus sanguineus) for Babesia vogeli in the Mediterranean region (Table 1 ).

B. burgdorferi, the pathogen responsible for Lyme borreliosis (LB), was named after Dr. Willy Burgdorfer, who first discovered the bacterium in ticks in 1981 (reviewed by Horst 2003; Skotarczak 2014). They represent relatively large, helical-shaped (spiral) bacteria belonging to the spirochaetes (order Spirochaetales). The $B b$ sl complex currently comprises 19 species, including at least five genospecies pathogenic to humans (Borrelia burgdorferi sensu stricto/Bbss, Borrelia afzelii, Borrelia bavariensis, Borrelia garinii and Borrelia spielmanii; Herzberger et al. 2007; Krupka and Straubinger 2010; Margos et al. 2013; Tijsse-Klasen et al. 2013b).
Based on current information, pathogenicity (in the course of experimental and natural infections) in the dog has been demonstrated conclusively only for $B b s s$, especially in the light of Koch's postulates complying after experimental infections (Hovius et al. 2000; Straubinger 2000; Straubinger et al. 2000; Liebisch and Liebisch 2003a; Littman et al. 2006; Wagner et al. 2012; Skotarczak 2014).

A. phagocytophilum is an obligate intracellular gram-negative bacterium, belonging to the order of Rickettsiales. This bacterium replicates mainly in neutrophils and can cause disease in humans, horses, dogs, cats and ruminants (Huhn et al. 2014). Since 2001, the former species Ehrlichia equi and Ehrlichia phagocytophila, and the agent responsible for human granulocytic ehrlichiosis ("HGE agent"), have been reclassified as a new species A. phagocytophilum on the basis of molecular data (16S rRNA gene; Dumler et al. 2001). These bacteria bind to glycoproteins on the surface of neutrophils and are incorporated into the cells through caveolae-mediated endocytosis. Thereafter, they prevent endosome-lysosome fusion and reproduce in membrane-bound vesicles, forming microcolonies called morulae (Carrade et al. 2009). A recent study showed furthermore that $A$. phagocytophilum was able to invade endothelial cells in vitro and that transmission of bacteria from microvascular endothelial cells to granulocytes occurred under flow conditions (Wang et al. 2015).

Babesia are protozoan agents belonging to the piroplasms (family Babesiidae, order Piroplasmida), and are the most important blood parasites found in domestic mammals. Canine babesiosis occurs worldwide. Intraerythrocytic parasites in dogs with symptoms comparable with babesiosis (fever, anaemia, splenomegaly) were first described in South Africa in 1893; in Europe, they were first described in Italy in 1895 , some years after bovine babesiosis was first described by the Romanian Victor Babes in 1888 (Babes 1888; Piana and GalliValerio 1895; Baneth 2013). Until a few years ago, canine babesiosis was induced by three species of a large Babesia (merozoite size 3-5 $\mu \mathrm{m}$ ), Babesia 
Table 1 Tick-borne infections: vectors, pathogens and occurrence (sources include Olmeda-Garcia et al. 1993; Dongus et al. 1996; de la Fuente et al. 2008; Brianti et al. 2012; Petney et al. 2012; Deplazes et al. 2013; lonita et al. 2013; Krücken et al. 2013; Tijsse-Klasen et al. 2013a; Najm et al. 2014; Rizzoli et al. 2014); * There is evidence that other Ixodes spp. such as I. hexagonus may also act as vectors for Lyme borreliae or Anaplasma phagocytophilum (Petney et al. 2012); ** Relative humidity; ${ }^{* *}$ Currently assumed to be a cryptic species complex under the name " $R$. sanguineus sensu lato" with several different species included, presumed different distribution, host specificity and vector competence (Dantas-Torres \& Otranto 2014a).

\begin{tabular}{|c|c|c|c|}
\hline Vectors & Appearance & Potential vector for... & $\begin{array}{l}\text { Occurrence in Germany } \\
\text { and Austria?; habitat }\end{array}$ \\
\hline $\begin{array}{l}\text { Ixodes ricinus: } \\
\text { the Castor bean } \\
\text { tick* }\end{array}$ & & $\begin{array}{l}\text { Borrelia burgdorferi / Borrelia miya- } \\
\text { motoi, Anaplasma phagocytophilum, } \\
\text { tick-borne encephalitis virus, louping } \\
\text { ill virus / Eyach virus / Tribec virus, } \\
\text { Babesia divergens / B. microti / } \\
\text { B. venatorum (B. capreoli, B. annae?), } \\
\text { Rickettsia helvetica / R. monacensis, } \\
\text { Candidatus Neoehrlichia mikurensis, } \\
\text { Bartonella henselae }\end{array}$ & $\begin{array}{l}\text { yes; humid habitats } \\
\left(>75 \% \mathrm{RH}^{* *}\right) \text { : especially } \\
\text { forest borders, roadsides, } \\
\text { extensively farmed pasture, } \\
\text { parks, gardens }\end{array}$ \\
\hline $\begin{array}{l}\text { Dermacentor } \\
\text { reticulatus: } \\
\text { the Ornate dog tick }\end{array}$ & & $\begin{array}{l}\text { Babesia canis / B. caballi, } \\
\text { Theileria equi, Francisella tularensis, } \\
\text { Rickettsia raoultii / R. slovaca / } \\
\text { R. helvetica }\end{array}$ & $\begin{array}{l}\text { yes; local foci: humid forest } \\
\text { and meadow habitats, } \\
\text { river banks }\end{array}$ \\
\hline $\begin{array}{l}\text { Rhipicephalus } \\
\text { sanguineus } * * \text { : } \\
\text { the Brown dog tick }\end{array}$ & & $\begin{array}{l}\text { Babesia vogeli / B. gibsoni, Anaplasma } \\
\text { platys, Ehrlichia / Hepatozoon canis, } \\
\text { Dipetalonema dracunculoides, } \\
\text { Cercopithifilaria spp., Rickettsia } \\
\text { conorii / R. massiliae, Bartonella } \\
\text { vinsonii subsp. berkhoffi }\end{array}$ & $\begin{array}{l}\text { only temporary as an } \\
\text { outdoor tick; locally as } \\
\text { an imported, indoor } \\
\text { ("domestic") populations } \\
\text { in yearround tempered } \\
\text { buildings }\end{array}$ \\
\hline
\end{tabular}

canis, Babesia vogeli and Babesia rossi (formerly Babesia canis subsp. canis, B. canis subsp. vogeli and $B$. canis subsp. rossi), and one small Babesia (1-3 $\mu \mathrm{m}$ ), B. gibsoni (Uilenberg et al. 1989; Zahler et al. 1998; Carret et al. 1999; Irwin 2009; Ogo et al. 2011). Recently, however, molecular studies resulted in the addition of further species. There are now at least nine genetically different species recognized (Tables $2-3$ ). The recent findings of Babesia annae in foxes in Germany, Austria and Hungary (see Table 3) are intriguing, as no concurrent infections in dogs were reported from the corresponding areas. The provisional assignment of this agent as "Theileria annae" is controversial, because the organism is phylogenetically closer to Babesia microti. Typical features of the genus
Theileria, such as pre-erythrocytic stages or paucity of transovarial transmission in the tick vector, have not been proven for B. annae (Dixit et al. 2010; Simões et al. 2011). One current study assign this organism as Babesia vulpes sp. nov., after its natural host Vulpes vulpes (Baneth et al. 2015).

\section{Prevalence/occurrence and distribution}

The first large-scale, methodically and geographically comprehensive serological analysis in the field of canine TBD in Germany was conducted in the form of a countrywide study with 5,881 samples from dogs tested (Krupka et al. 2007). Serum samples from 3,005 dogs (group A; not pre-selected) and 2,876 dogs (group B; showing symptoms of borreliosis) were submitted to two different 
Table 2 Current Babesia species in the dog (large forms): at least six genetically different species / isolates (according to Beck et al. 2009; Irwin 2009; Birkenheuer 2012).

\begin{tabular}{|c|c|c|c|c|}
\hline Species & Synonym & Vector & Distribution & $\begin{array}{l}\text { special features / } \\
\text { clinical findings }\end{array}$ \\
\hline Babesia vogeli* & $\begin{array}{l}\text { Babesia canis } \\
\text { subsp. vogeli }\end{array}$ & $\begin{array}{l}\text { Rhipicephalus } \\
\text { sanguineus }\end{array}$ & $\begin{array}{l}\text { global throughout the } \\
\text { tropics and subtropics, } \\
\text { Mediterranean region }\end{array}$ & $\begin{array}{l}\text { in colder zones, vector also } \\
\text { adapted to indoor, year-round } \\
\text { tempered climate of buildings }\end{array}$ \\
\hline Babesia canis & $\begin{array}{l}\text { Babesia canis } \\
\text { subsp. canis }\end{array}$ & $\begin{array}{l}\text { Dermacentor } \\
\text { reticulatus }\end{array}$ & Europe & $\begin{array}{l}\text { haemolytic anaemia, fever; } \\
\text { moderate virulence }\end{array}$ \\
\hline Babesia rossi & $\begin{array}{l}\text { Babesia canis } \\
\text { subsp. rossi }\end{array}$ & $\begin{array}{l}\text { Haemaphysalis } \\
\text { elliptica }\end{array}$ & $\begin{array}{l}\text { Sub-Saharan Africa; } \\
\text { South Africa }\end{array}$ & $\begin{array}{l}\text { haemolysis, immune disease; } \\
\text { high virulence }\end{array}$ \\
\hline Babesia sp.** & $\begin{array}{l}\text { unnamed large } \\
\text { Babesia sp. } \\
\text { ("North Carolina"/ } \\
\text { NC isolate) }\end{array}$ & $\begin{array}{l}\text { at present } \\
\text { unknown }\end{array}$ & North Carolina (USA) & $\begin{array}{l}\text { thrombocytopenia, haemolytic } \\
\text { anaemia, leukopenia, pigmen- } \\
\text { turia }\end{array}$ \\
\hline Babesia sp. & $\begin{array}{l}\text { unnamed large } \\
\text { Babesia sp. } \\
\text { (UK isolate) }\end{array}$ & $\begin{array}{l}\text { at present } \\
\text { unknown }\end{array}$ & United Kingdom & $\begin{array}{l}\text { thrombocytopenia, haemolytic } \\
\text { anaemia, leukopenia, pigmen- } \\
\text { turia }\end{array}$ \\
\hline Babesia caballi & - & $\begin{array}{l}\text { unknown } \\
\text { (D. reticulatus?) }\end{array}$ & Croatia & molecular detection only \\
\hline \multicolumn{5}{|c|}{$\begin{array}{l}\text { *shows weak virulence for adult dogs but can also take a severe course in the presence of predisposing factors (young } \\
\text { dogs, immunosuppression (Cushing's disease, corticosteroid administration or co-infections)); **apparently the Babesia } \\
\text { species from NC ("Babesia sp. coco") affect mainly immunosuppressed dogs; in vitro, it shows few ultrastructural dif- } \\
\text { ferences compared to other Babesia spp.; according to the phylogenetic results (18S rRNA) of a current study, this large } \\
\text { piroplasm from NC could be related to the genus Rangelia (Eiras et al. 2014) }\end{array}$} \\
\hline
\end{tabular}

laboratories where they were investigated using a serological rapid test $\left(\mathrm{SNAP}^{\circledR} 4 \mathrm{Dx}^{\circledR}\right)$ for the presence of specific antibodies to Borrelia $\mathrm{C} 6$ antigen (not induced by vaccination, see below). In group A, $7.7 \%$ of the dogs $(232 / 3,005 ; 95 \%$ confidence interval (CI): $6.8-8.7)$ and $11.8 \%$ of the dogs in group B (340/2,876; 95\% CI: $10.7-13.1)$ tested positive (statistically significant difference of $p<0.001$; chi-square (CS) test). Overall, regional seroprevalences of $1.9 \%$ to $10.3 \%$ were found for B. burgdorferi (group A). Similar seroprevalence was observed for humans in a recent study from Germany $(9.4 \% ; 741 / 6,945)$, with significant correlation for seropositivity in southern Germany, male sex and residence in rural areas. Interestingly, having a dog/cat in the house was not associated with a higher risk for seropositivity (Wilking et al. 2015). Within the above mentioned canine group A $3 \%$ of the dogs $(91 / 3,005 ; 95 \%$ CI: $2.4-3.7)$ also showed antibodies to A. phagocytophilum (Fig. 1).
The seroprevalence for $A$. phagocytophilum (total samples tested 5,683; antibodies to MSP2 (P44) antigen) was $21.5 \%$ (95\% CI: $20.5-22.6$ ). It can therefore be assumed that at least one fifth of dogs in Germany had contact with this agent. Overall, regional seroprevalences of $17.6 \%$ to $31.1 \%$ were found for Anaplasma spp. (Krupka et al. 2007). In comparison, the seroprevalence with the same test $\left(\mathrm{SNAP}^{\circledR} 4 \mathrm{Dx}^{\circledR}\right.$ ) for Borrelia and Anaplasma in Poland (3,094 canine samples) was $3.75 \%$ and $12.31 \%$, respectively (Krämer et al. 2014). Even lower rates (1.09\% for Borrelia and $2.72 \%$ for Anaplasma) were found in in France (the same test; 919 dogs; Pantchev et al. 2009).

To document the presence of A. phagocytophilum and $B b s l$ in dogs in Austria, routine diagnostic data from the authors' laboratory were evaluated retrospectively (previously unpublished data; methods according to Dyachenko et al. 2012). In April/May 2011, Anaplasma spp. real-time PCR was used to 


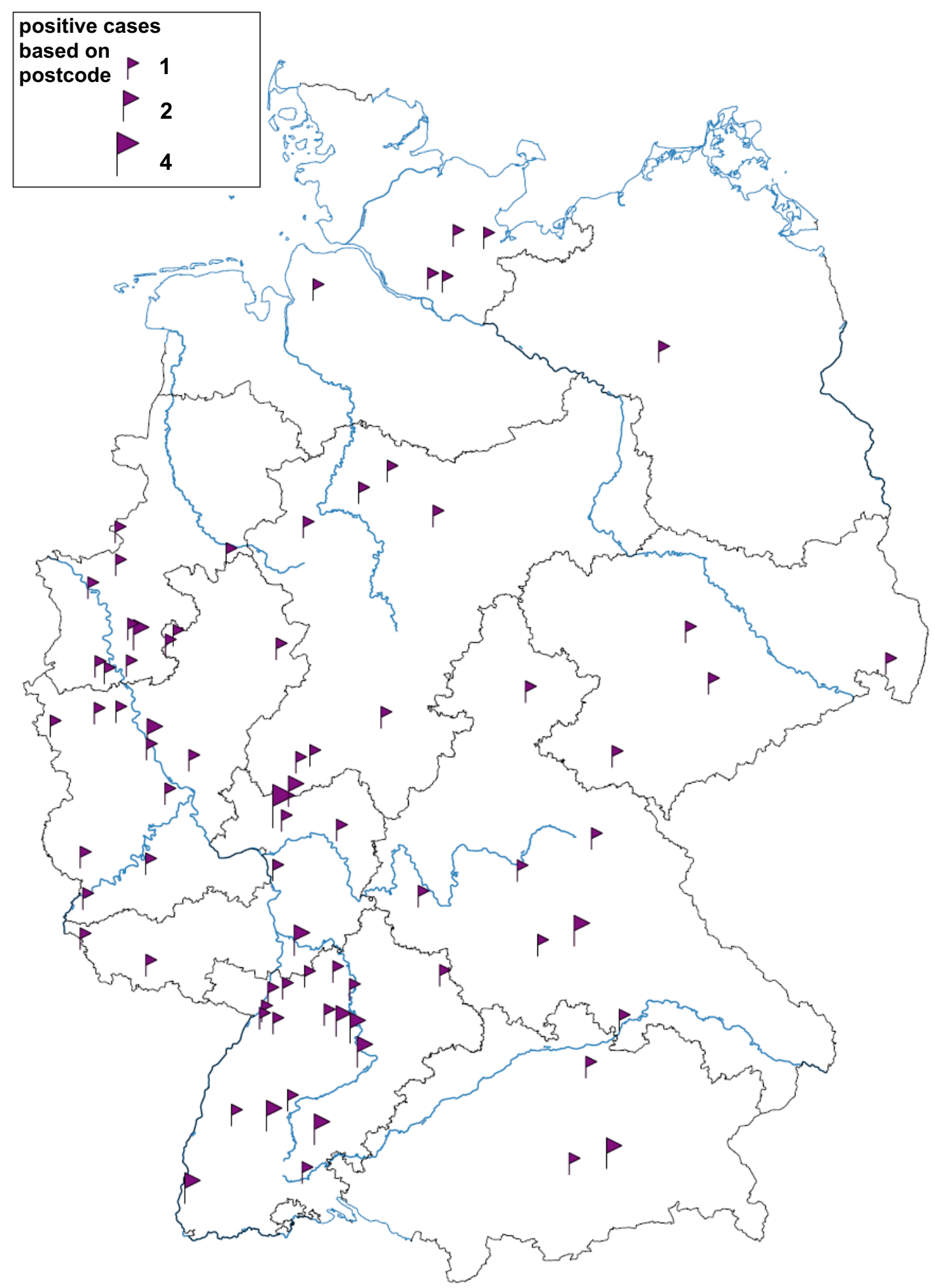

Fig. 1 Anaplasma phagocytophilum and Borrelia burgdorferi in Germany: origin of simultaneously detected antibodies by postcode (map produced using EasyMap; positions correspond to submitters' postcodes). 
Table 3 Current Babesia / Theileria species in the dog (small forms): at least five genetically different species (according to Zahler et al. 2000a, b; Beck et al. 2009; Irwin 2009; Birkenheuer 2012; Falkenö et al. 2013; Najm et al. 2014; Duscher et al. 2014; Gallusova et al. 2014; Rosa et al. 2014; Baneth et al. 2015; Farkas et al. 2015).

\begin{tabular}{|c|c|c|c|c|}
\hline Species & Synonym & Vector & Distribution & $\begin{array}{l}\text { special features / } \\
\text { clinical findings }\end{array}$ \\
\hline Babesia gibsoni & $\begin{array}{l}\text { Babesia gibsoni } \\
\text { Asia strain }\end{array}$ & $\begin{array}{l}\text { Haemaphysalis } \\
\text { bispinosa, Haema- } \\
\text { physalis longicor- } \\
\text { nis, (Rhipicephalus } \\
\text { sanguineus) }\end{array}$ & $\begin{array}{l}\text { mainly in Asia, } \\
\text { sporadically also in } \\
\text { Africa, Australia, } \\
\text { Europe, North and } \\
\text { South America }\end{array}$ & $\begin{array}{l}\text { outside Asia, infection } \\
\text { often associated with } \\
\text { pit bull terriers and other } \\
\text { fighting dogs with non } \\
\text { vector-borne transmission }\end{array}$ \\
\hline $\begin{array}{l}\text { Babesia } \\
\text { conradae }\end{array}$ & $\begin{array}{l}\text { "Small Babesia sp." } \\
\text { California isolate }\end{array}$ & $\begin{array}{l}\text { unknown (a wild } \\
\text { animal reservoir is } \\
\text { assumed) }\end{array}$ & California & $\begin{array}{l}\text { haemolytic anaemia, } \\
\text { vomitus }\end{array}$ \\
\hline Babesia annae & $\begin{array}{l}\text { Babesia microti-like, } \\
\text { Theileria annae; } \\
\text { Babesia vulpes sp. } \\
\text { nov.; Babesia Span- } \\
\text { ish dog isolate }\end{array}$ & $\begin{array}{l}\text { Ixodes spp. } \\
\text { (assumed) }\end{array}$ & $\begin{array}{l}\text { Northwest Spain, Por- } \\
\text { tugal, Croatia, Sweden, } \\
\text { USA; Germany / Austria } \\
\text { / Hungary (only in fox) }\end{array}$ & $\begin{array}{l}\text { severe haemolytic } \\
\text { anaemia, eosinophilia, } \\
\text { renal involvement }\end{array}$ \\
\hline Theileria equi & Babesia equi & unknown & $\begin{array}{l}\text { Spain, Croatia, France, } \\
\text { Romania, Jordan; } \\
\text { South Africa }\end{array}$ & $\begin{array}{l}\text { molecular detection only; } \\
\text { thrombocytopenia, } \\
\text { anaemia }\end{array}$ \\
\hline $\begin{array}{l}\text { Theileria } \\
\text { annulata }\end{array}$ & - & unknown & Spain & molecular detection only \\
\hline Theileria sp. & $\begin{array}{l}\text { unnamed Theileria } \\
\text { sp., South African } \\
\text { Theileria sp. }\end{array}$ & unknown & South Africa & $\begin{array}{l}\text { molecular detection only; } \\
\text { thrombocytopenia, } \\
\text { anaemia }\end{array}$ \\
\hline
\end{tabular}

test a total of 50 EDTA blood samples submitted by veterinarians in Austria (this test had been specifically requested, so the dogs were presumably showing clinical signs of infection). Eight out of 50 samples (16\%; 95\% CI: 7.1-29.1) tested positive. In comparison, a total of 30 samples were tested in the same period in 2010; five of these tested positive (16.7\%; $95 \%$ CI: 5.5-34.7). One hundred and sixty-four dogs were tested serologically for antibodies to Borrelia spp. C6 antigen in April/ May 2011 (serum samples; again submitted by Austrian veterinary surgeons specifically requesting this test), and seven were positive (4.3\%; $95 \%$ CI: 1.7-8.6). In comparison, a total of 90 samples were tested in the same period in 2010; five of these tested positive (5.6\%; $95 \%$ CI: $1.8-12.5)$. Strikingly, much larger numbers of samples were submitted for both tests in 2011 (increases of approx. $67 \%$ and $83 \%$ respectively compared with 2010 ). However, the differences in positive percentages for the two years were not statistically significant ( $\mathrm{p}=0.644$ for Borrelia and $\mathrm{p}=0.938$ for Anaplasma spp.; CS test). Regarding the distribution of positive samples, some federal states showed an overlapping incidence of both organisms (Vienna, Lower/Upper Austria and Carinthia). In other regions, only Anaplasma (Vorarlberg, Styria and Burgenland) or only Borrelia (Tirol) was detected. Salzburg was the only state with no positive cases (Fig. 2).

Previously, canine babesiosis was typically associated with travel to Mediterranean countries. In a study conducted in 2005 and 2006, blood samples from 5,483 dogs living in Germany with a history of travel were tested for relevant pathogens. Babesia species (DNA detection by means of conventional PCR technique) were detected in $2.4 \%$ of these samples (Hirsch and Pantchev 2008). However, canine babesiosis is increasingly endemic in both Germany (Barutzki et al. 2007) and Switzerland 
Fig. 2 A. phagocytophilum (blue; real-time PCR) occurrence and B. burgdorferi (red; anti-C6 antibodies) seroprevalence in Austria: origin of positive samples by postcode (map produced using RegioGraph; positions correspond to submitters' postcodes).

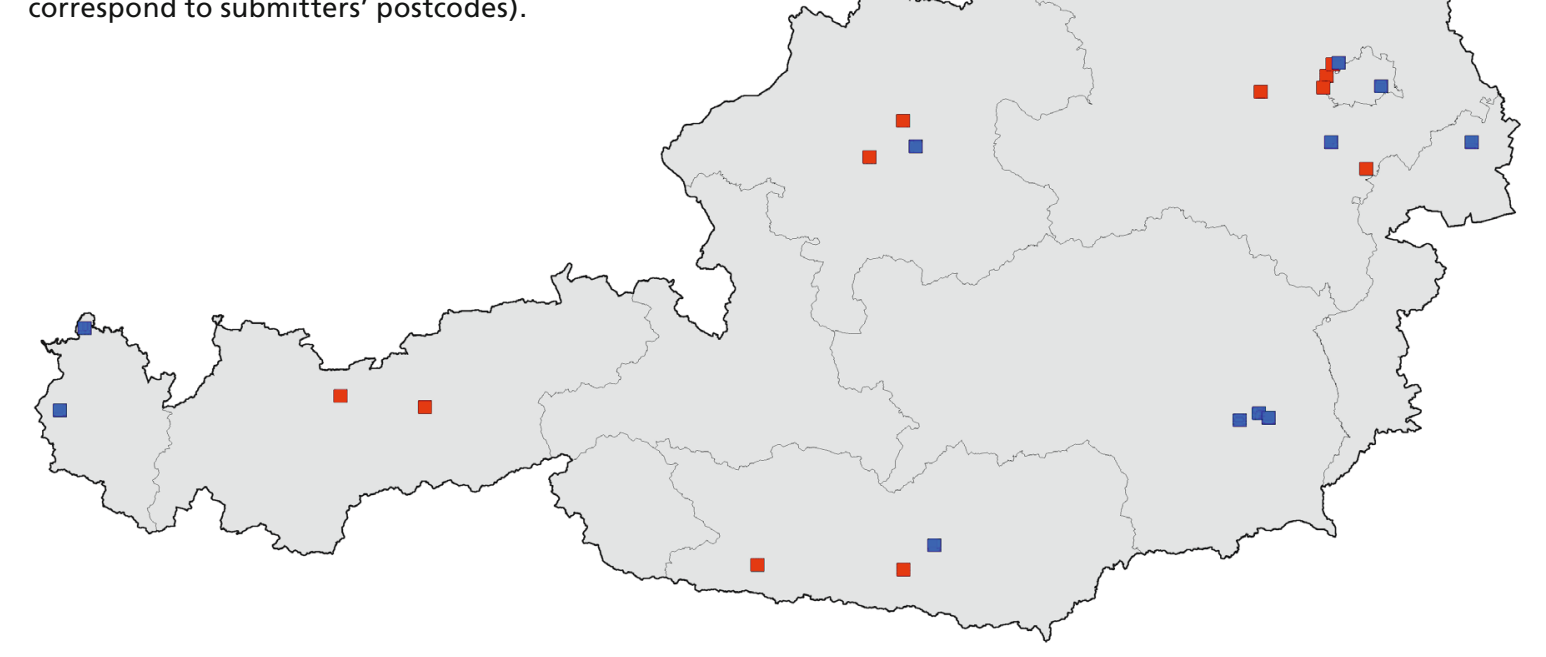

(Schaarschmidt et al. 2013). This is believed to be the result of dogs introducing infected ticks, which have subsequently found suitable biotopes (for example, due to re-naturalization of agricultural areas) and climatic conditions (Heile et al. 2006). In a recent study, a new $B$. canis ELISA was used to test 4,579 canine samples from Germany for B. canis antibodies as part of travel disease profiles (no immediate suspicion of babesiosis) and 937 samples from dogs with suspected babesiosis (Pantchev 2012a). Because a travel disease profile had been ordered, the dogs in the first group were assumed to have travelled outside Germany; in the second group, a history of travel could not be entirely ruled out. According to the test manufacturer, the sensitivity and the specificity of the B.canis ELISA compared with the indirect immunofluorescence assay (IFA) (671 sera tested using four different IFAs) are $91.6 \%$ and $95.4 \%$, respectively. In relation to a "gold standard" IFA validated at a university institute according to strict scientific criteria (287 sera), sensitivity and specificity are as high as $96.3 \%$ and $100 \%$. This ELISA is currently the only test authorized by the German Friedrich Löffler Institute for the detection of B. canis-specific antibodies in dogs. However, it shows cross-reactivity with other Babesia spp. (such as B.vogeli, Dyachenko et al. 2012) as well as B.gibsoni and Rangelia vitalii (own unpublished observations; see below). This whole-cell based assay can therefore be regarded as more piroplasma-specific. Three hundred and nineteen dogs (travel disease profile) within the above-mentioned study tested positive for antibodies (7\%; 95\% CI: 6.2-7.7) and a further 112 samples were borderline (2.4\%). In dogs with suspected babesiosis, higher proportions of samples were seropositive $(12.7 \%$; $95 \% \mathrm{CI}$ : $10.6-15$; significant difference of $\mathrm{p}<0.001$, CS test) and $3.5 \%$ of samples were borderline. Regarding the distribution of positive samples in both groups within the German federal states, it can be observed, that only dogs with a history of travel tested positive in four federal states, and one state had no cases at all (Fig. 3). Whether this result is due to the absence of endemic canine babesiosis in these states, or to the simple fact that insufficient samples were submitted, should be a subject for further studies.

The occurrence and distribution of B. canis infection in dogs in Austria was established using the 


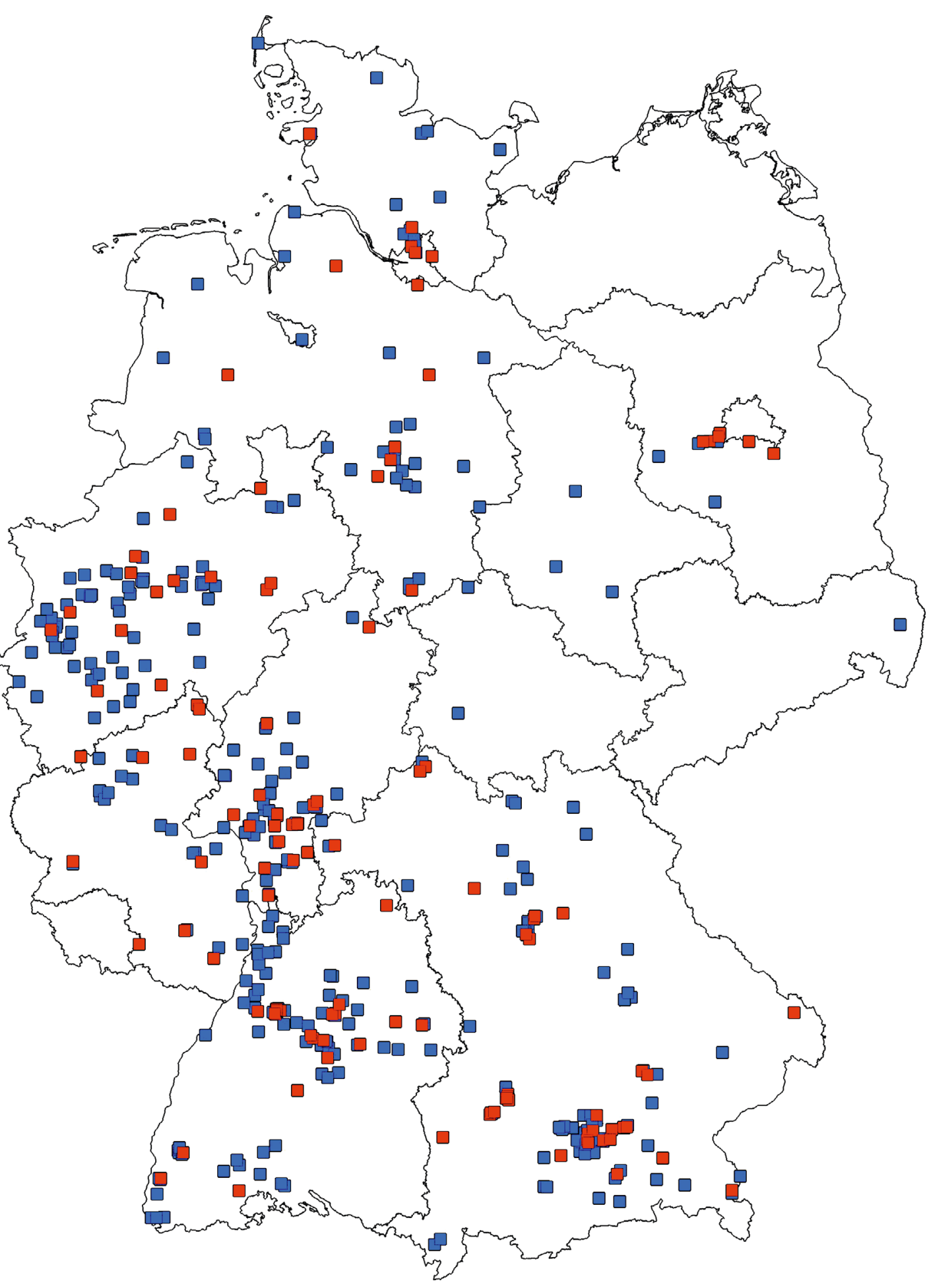

Fig. 3 Babesia canis in Germany: Origin of seropositive dogs with a history of travel (blue; $\mathrm{n}=319$ ) and suspected babesiosis (red; $n=119$; according to Pantchev 2012a; map produced using RegioGraph; positions correspond to submitters' postcodes). 
Fig. 4 Babesia canis seroprevalence in Austria: origin of seropositive dogs in group 1 (predominantly tested as part of a tick profile; red, $n=28$ ) and group 2 ("travel disease profile"; blue, $n=8$; map produced using RegioGraph, positions correspond to submitters' postcodes).

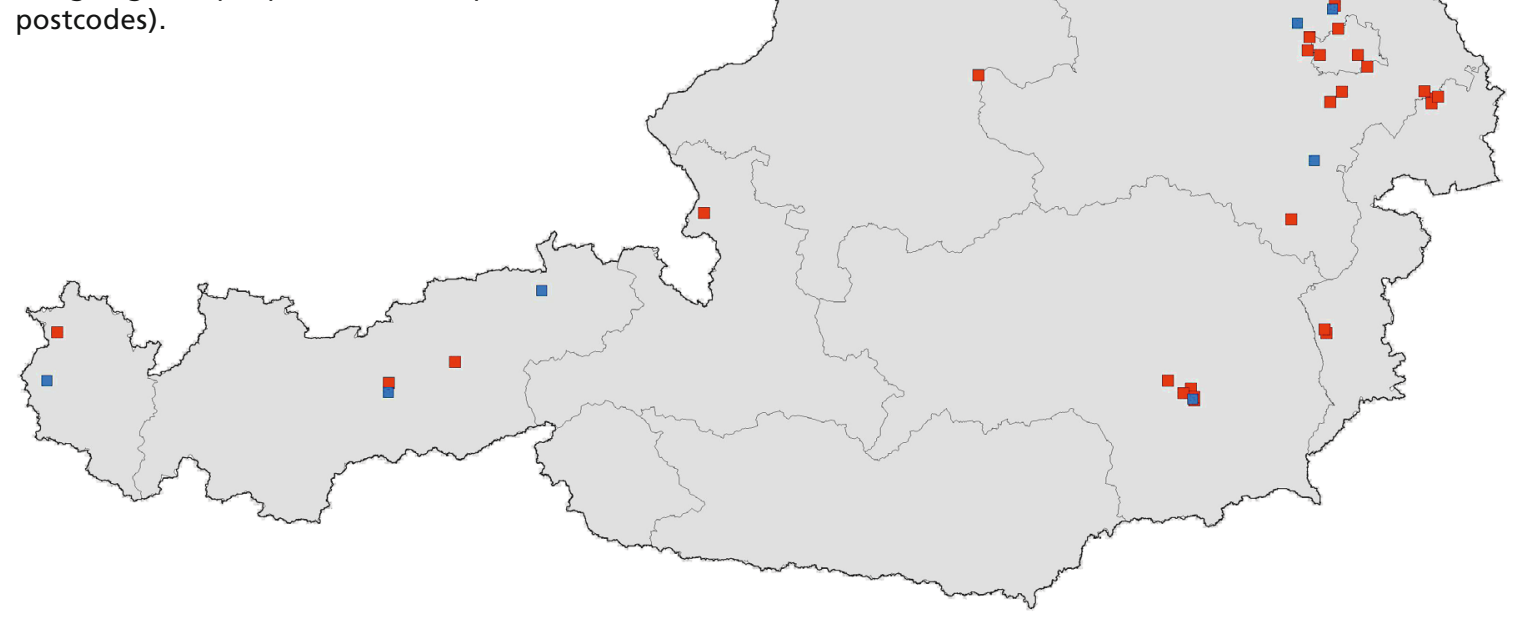

same Babesia ELISA (see above; previously unpublished data). The serum samples were submitted to the authors' laboratory by veterinarians in Austria from 2012 to 2013. Two hundred and fifty-nine samples in group 1 were tested either in response to a direct request for a Babesia spp. antibody test $(\mathrm{n}=70 ; 27 \%)$ or as a part of a serological tick profile $(\mathrm{n}=189 ; 73 \%)$. As a comparison, a second group was assessed over the same time period (group 2; $\mathrm{n}=172$ ). Animals in group 2 were assumed to have a travel history, because the serum samples were submitted by the veterinarian as part of a travel disease profile. In group 1 (mostly comprising "tick profiles") 28 samples tested positive (10.8\%; $95 \%$ CI: 7.3-15.2; red in Fig. 4) and 6 samples were borderline (2.3\%). As part of the travel disease profile, however, only 8 dogs tested positive $(4.7 \%$; $95 \%$ CI: $2-9$; blue in Fig. 4), which is significantly fewer than in group 1 ( $p=0.024$; CS test). Additionally, six samples in group 2 tested borderline (3.5\%). As can be deduced from Figure 4, there appears to be a cluster of seropositive dogs in the eastern part of Austria.
Pathogen transmission and incubation period Various mechanisms are required to activate the relevant pathogen in the tick. In general, transmission of bacteria and parasites does not occur immediately. The shortest transmission intervals reported are 16 to 65 hours for Borrelia and 24 hours for Anaplasma (Crippa et al. 2002; Kahl et al. 1998; Diniz and Breitschwerdt 2012). Borrelia spp. produce various outer surface proteins ("Osp"), which enable the spirochaetes to adapt to a wide range of environmental conditions (Kenedy et al., 2012). Borrelia organisms in the tick's gut express mainly OspA, which allows the bacteria to adhere to the tick receptor for OspA ("TROSPA"; Tsao 2009). Contact with the host's skin causes a temperature rise in the tick, which triggers an activity signal in Borrelia organisms, enabling them to migrate from the tick's gut to its salivary glands. Following contact with blood, OspA (and OspB) are replaced within 36 to 48 hours by newly produced OspC, which binds to the tick salivary protein Salp15 (Kenedy et al. 2012). After 24 to 48 hours, Borrelia organisms are transmitted to the dog (Radolf and Caimano 2008; Straubinger and Pantchev 2010). In the mammalian host, 


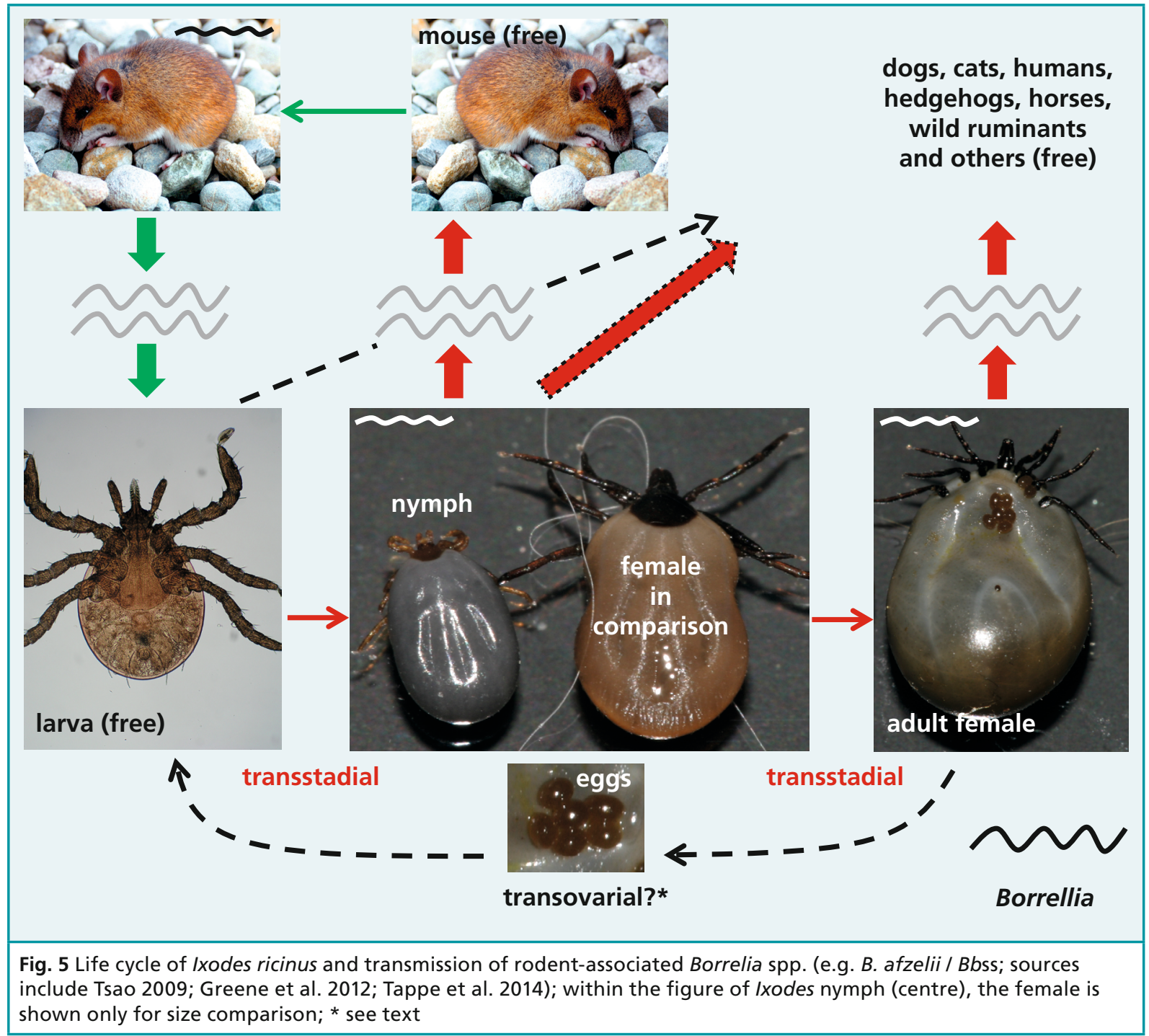

spirochaetes express the protein VlsE (variable major protein-like sequence, expressed) on their surface. The variability of this protein allows Borrelia to evade the host's immune defences (Kenedy et al. 2012). A shift in the outer surface proteins seems to be crucial for infection (Appel et al. 1993; Radolf and Caimano 2008). In experimental studies it was shown that the incubation period in the dog is between two and five months (Appel et al. 1993; Straubinger 2000; Straubinger et al. 2000; Wagner et al. 2012). Therefore, no clinical signs were observed in dogs that had not previously seroconverted (Appel et al. 1993). In contrast, the incubation period for anaplasmosis following a tick bite or experimental (i.v.) infection is reported to be 1 to 2 weeks (Scorpio et al. 2011; Diniz and Breitschwerdt 2012), which can precede seroconversion (see below). Shorter transmission intervals may exceptionally occur. For example, occasional cases of systemic infection with Borrelia spp. in the tick were described, with Borrelia present in the salivary glands before tick attachement (also described for A. phagocytophilum; Crippa et al. 2002; Diniz and Breitschwerdt 2012). Earlier transmission is also possible, if previously attached (and thus "activated") ticks infest a new host. Moreover, 
I. ricinus appears to transmit B. afzelii more rapidly than Bbss (Crippa et al. 2002; Moehrle and Rassner 2002). It is generally assumed that transmission of $B b s l$ takes place via nymphs and adult ticks, and specifically that larvae become infected by feeding on infected reservoir hosts (e.g. rodents), followed by transstadial transmission of Borrelia (illustrated in Fig. 5; applies similarly to A. phagocytophilum). Whether a transovarial transmission of $B b s l$ can take place in the tick, as proposed following increased molecular detection in larvae in a recent study (Tappe et al. 2014), or the transovarially transmitted agent is actually Borrelia miyamotoi (Rollend et al. 2013), has to be evaluated in further studies. Even if larvae did contain Bbsl in sufficient amounts for transmission, the risk to dogs is put into perspective by the fact that these larvae live primarily at ground level, and their preferred hosts are small mammals and birds (Liebisch and Liebisch 2003b; Greene et al. 2012; Deplazes et al. 2013). This is supported by a recent study from Switzerland, in which only $0.5 \%$ of collected ticks from dogs we identified as being larvae (Eichenberger et al. 2015). Non-vector-borne transmission of A. phagocytophilum in humans through blood transfusions (Annen et al. 2012) or perinatal infection (Horowitz et al. 1998; Dhand et al. 2007) has been described. Moreover, transplacental transmission as a result of experimental infection is possible in ruminants (Diniz and Breitschwerdt 2012) and was also confirmed after natural congenital infection in a calf in northern Germany (Henniger et al. 2013). Vertical transmission of $B b s s$ did not occur under experimental conditions in dogs (maternal antibodies declined to negative 4 weeks postpartum; Appel et al. 1993). Vertical transmission of Borrelia spp. and other non-vectorborne modes of transmission (via semen, urine, or blood) are unlikely in the dog under natural conditions (Appel et al. 1993; Greene et al. 2012). According to guidelines on the collection, storage, transport and administration of blood and blood products in veterinary medicine, issued by the German Federal Office of Consumer Protection and
Food Safety, dogs used as blood donors in Germany should be tested by PCR for Anaplasma spp. (A. phagocytophilum) and Babesia spp. (B. canis; see below), depending on the region and the prevailing epidemiological situation http://www.bvl.bund.de/ DE/05_Tierarzneimittel/05_Fachmeldungen/2011/ leitlinien_blutprodukte.html?nn=1644492).

A striking feature of Babesia species is not only the transstadial but also the efficient transovarial transmission in the tick. By means of vertical transmission to the next 3 to 4 generations, tick populations in an endemic region can remain infected for several years, despite having no opportunity for reinfection (Deplazes et al. 2013). This ensures long-term survival in the tick population (distribution strategy; Chauvin et al. 2009). This process is limited to some extent because only 10 to $20 \%$ of the tick eggs are infected, and infected females produce fewer eggs (Deplazes et al. 2013). The development of Babesia in the tick, specifically the infestation of the salivary glands accompanied by the production of sporozoites, does not happen immediately, but is triggered by nervous stimulation of various organs. When ticks attach to the host, developmental stages of Babesia known as kinetes are released. These enter the tick's salivary glands via the haemolymph. Dogs exposed experimentally to $D$. reticulatus containing $B$. canis tested positive for Babesia (PCR, blood smears) after a 72-hour infestation; males which had already had a blood meal were an exception in terms of immediate transmission (Heile and Schein 2007). The same study showed that nymphs already have the ability to transmit $B$. canis. However, because nymphs rarely infest dogs, this mode of transmission plays only a minor role from an epidemiological perspective. The incubation period of Babesia in the dog is reported to be 7 to 21 days p.i. (Belton 2003; Deplazes et al. 2006). Non-vector-borne transmission routes may include blood transfusion, as shown in the case of $B$. canis in an experimental design (Brandao et al. 2003) or in the case of B. gibsoni (Belton 2003; Boozer and Macintire 2005). In regard to $B$. gibsoni, there is also speculation about 
direct dog-to-dog transmission via bite wounds, saliva or ingested blood (fighting dogs), and transplacental transmission (B. canis, B. gibsoni and B. annae) also appears to be possible (Belton 2003; Boozer and Macintire 2005; Irwin 2009; Ayoob et al. 2010; Ogo et al. 2011; Simões et al. 2011; Mierzejewska et al. 2014).

\section{Diagnostics}

\section{Lyme borreliosis (LB)}

The presumptive diagnosis of LB in dogs implies several criteria (according to Littman et al. 2006; Krupka and Straubinger 2010). These include a history with regard to tick exposure and living in endemic regions, diagnostic evidence of infection with the pathogen, exclusion of differential diagnoses, compatible clinical symptoms, and response to specific treatment including monitoring of treatment success. Detection by direct methods (PCR and/or culture) ante mortem is difficult and of little practical relevance. Borrelia organisms are rarely detected in body fluids such as blood (Fig. 6), urine (bladder involvement is also rare), synovial fluid or cerebrospinal fluid (Leschnik et al. 2010; Krimer et al. 2011; Susta et al. 2012). They are more commonly found in connective tissue, fascias, joint capsule (most promising in the affected joint), skin (near the tick bite), lymph nodes, muscle (including the heart), etc. (frequently in low numbers at the time of detection; Appel et al. 1993; Chang et al. 1996; Straubinger 2000; Chou et al. 2006). The majority of dogs first develop lameness in the joint closest to the site of tick attachment, which further supports the fact that $B$. burgdoferi does not disseminate throughout the body via the blood stream (Straubinger et al. 1998). Direct methods in many cases produce false-negative results, because tissue samples commonly contain few or no bacteria at the time of collection, so serology is widely used. However, the only reliable way to differentiate the genospecies is direct detection followed by molecular characterization (as is frequently performed

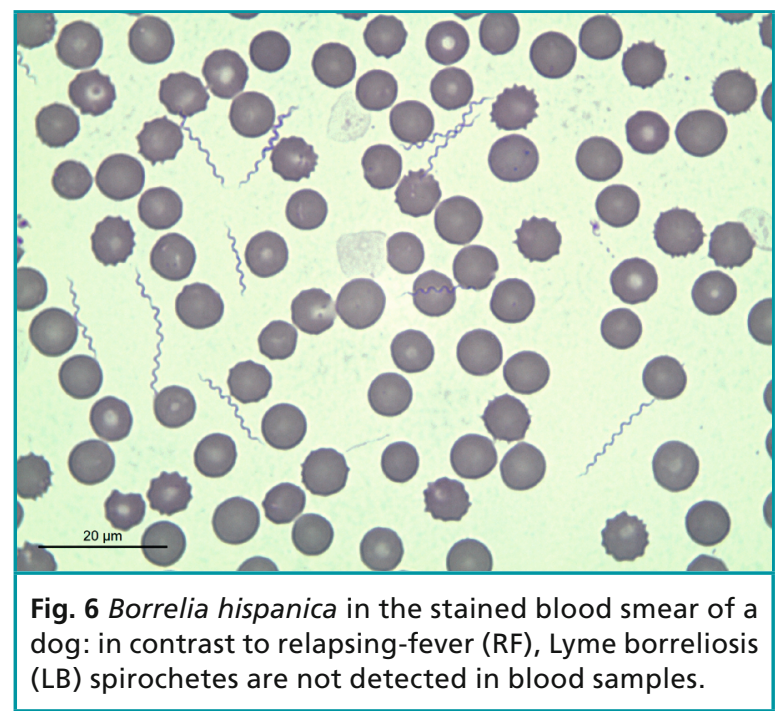

in tick studies; Skotarczak 2014), because the relevant antigens display serological cross-reactivity (Hovius et al. 2000). As a result, it is not currently possible to use different serological tests (enzyme immunoassays or immunoblots) based on individual genospecies or their antigens to perform reliable serological differentiation (Kurzova et al. 2014).

Four aspects should be considered when interpreting positive serological results. Serological tests detect circulating antibodies to an infectious agent, which may indicate active infection with that agent, previous infection or exposure, vaccination, or cross-reactivity with another (generally closely related) organism. These points should be considered, when evaluating serological tests for Borrelia spp.-specific antibodies. In human and veterinary medicine, antibody detection using specific peptides such as $\mathrm{C} 6$ is becoming increasingly popular (e.g. Liang et al. 1999a; Embers et al. 2007; Krupka and Straubinger 2010; Wagner et al. 2012), as they show advantages over other methods, taking into account the four points mentioned above. The C6 peptide is part of VlsE, a 35-kDa surface lipoprotein of Borrelia burgdorferi (Kenedy et al. 2012). IR6 (synthetic peptide $=\mathrm{C} 6$ ) is the most immunodominant of six invariable regions $\left(\mathrm{IR}_{1}-\mathrm{IR}_{6}\right)$ within the central variable domain (six variable regions, $\mathrm{VR}_{\mathrm{I}}-\mathrm{VR}_{\mathrm{VI}}$, interlaced with the invariable regions; 


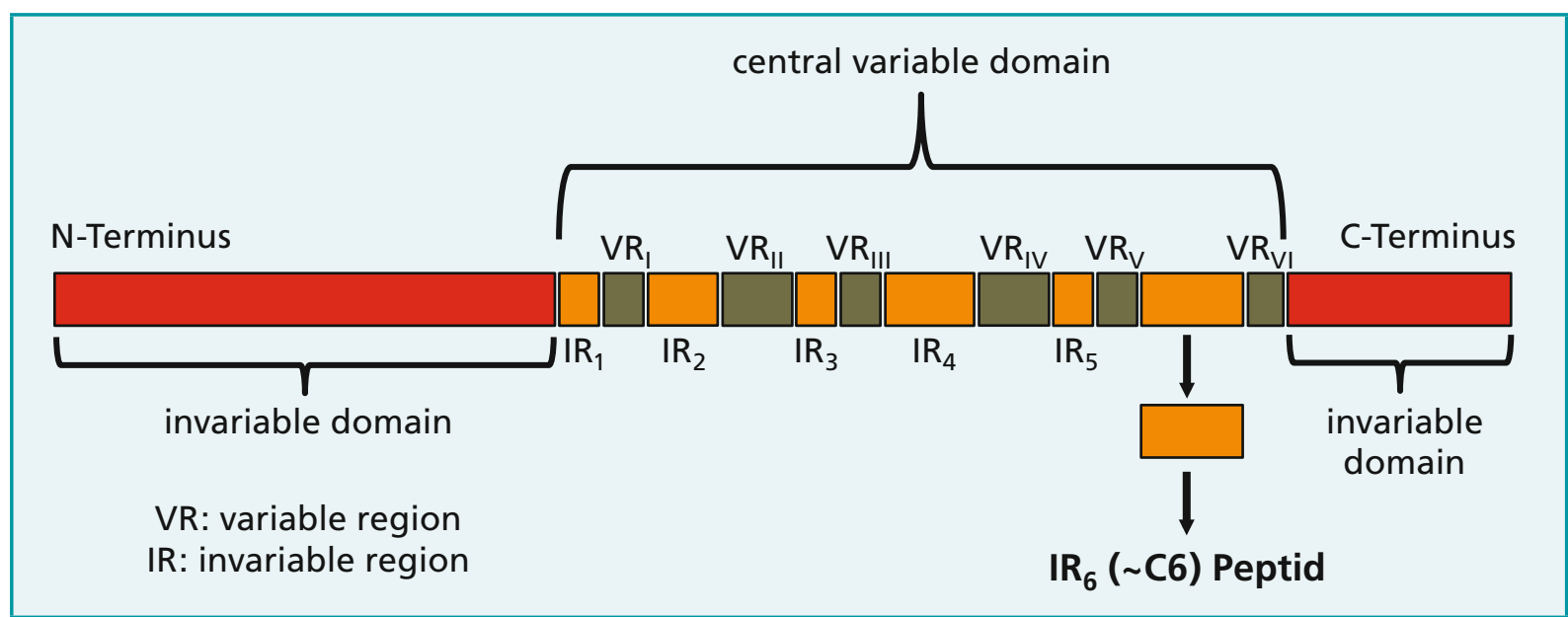

Fig. 7 Structure of VIsE and origin of C6 (modified according to Liang et al. 2000b).

Liang et al. 1999b; Embers et al. 2007; Fig. 7). In addition, $\mathrm{C} 6$ is conserved among different Borrelia species (Liang et al. 2000a). The $\mathrm{VlsE}$ gene locus is located on a plasmid (lp28-1; Brisson et al. 2012; Embers et al. 2012), its expression is suppressed in the tick (Bykowski et al. 2006; Tilly et al. 2013) and drastically upregulated in the host. Moreover, recombination takes place only in the host, not in the tick or in in vitro cultures (Lin et al. 2009). Antibodies to Borrelia $\mathrm{C} 6$ antigen are not induced by vaccination in the dog (O'Connor et al. 2004; Goldstein et al. 2007), possibly due to lost of VlsE expression after repeated serial passage of cultured spirochaetes (Liang et al. 1999a,b; O'Connor et al. 2004; Lin et al. 2009). According to current scientific knowledge, VlsE is also one of the most important virulence factors of Lyme borreliae, preventing their elimination by the immune system and triggering a persistent infection in the host. This is made possible by constant alternation in the six variable regions (Lin et al. 2009; Brisson et al. 2012; Kenedy et al. 2012).

The advantage of Borrelia C6-based tests over previous methods (IgM/IgG-ELISA or IFA) is the absence of a cross-reaction with vaccine-induced antibodies (O'Connor et al. 2004; Töpfer 2005; Goldstein et al. 2007) or with antibodies to other spirochaetes such as Leptospira (Liang et al. 2000b).
Thus, C6 represents a diagnostic approach that facilitates DIVA (Differentiation of Infected from Vaccinated Animals). Whole-cell-based assays can cross-react with other spirochaetes as shown e.g. for Leptospira species (Štefančikova et al. 2008) or with vaccination (e.g. Gauthier and Mansfield 1999; Straubinger et al. 2002; Töpfer 2005). Anti-C6 antibodies also represent an early marker of infection from 21 to 35 days p.i. (Wagner et al. 2012) and persist for at least 12 months in untreated dogs (Levy et al. 2008). After treatment, anti-C6 antibody concentrations (ACAC) may drop within 3 to 6 months (a decrease of more than $58.3 \%$ was seen after 6 months in animals with an initial concentration over $29 \mathrm{U} / \mathrm{ml}$; Levy et al. 2008), whereas the values in whole-cell-based tests and OspFbased tests do not fall to the same extent (Straubinger 2000; Straubinger et al. 2000; Littman 2013; Fig. 8). Additionally, Goldstein et al. (2007) showed a $93 \%$ correlation between a commercially available C6 test and an immunoblot test with regard to the diagnosis of natural infection in the dog. Thus the last two criteria (antibody persistence and decrease in concentration after treatment) also emphasize that $\mathrm{C} 6$ can be viewed as a marker of active infection and can be used to monitor treatment success. This has also been shown in experimental infection in monkeys (Embers et al. 2012). 


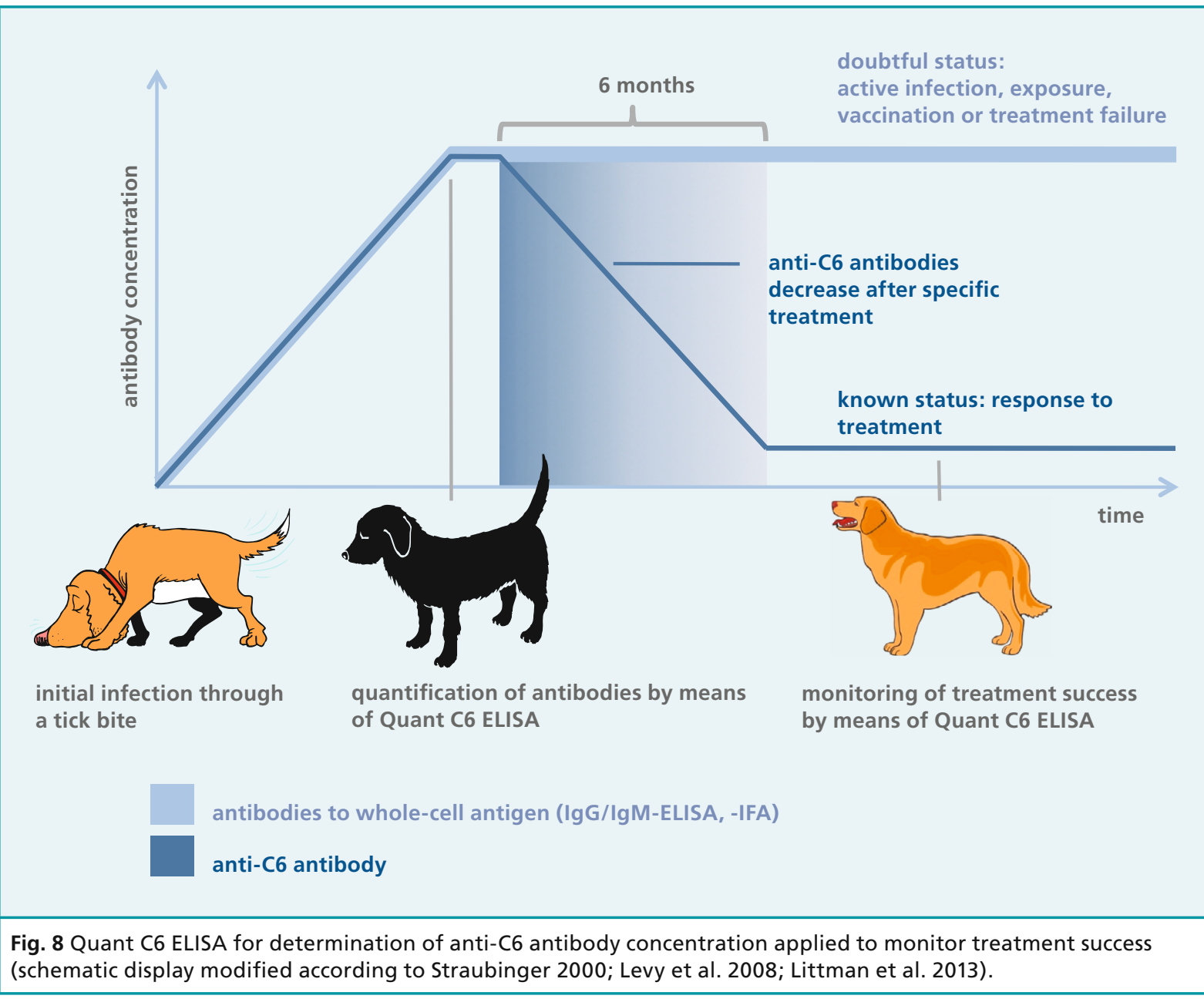

For correct diagnosis it is also important to rule out potential differential diagnoses, bearing in mind the travel history of the dog and potential infections from abroad such as Leishmania infantum or Ehrlichia canis. Useful tests in this regard are listed by Littman et al. (2006), Greene et al. (2012) and Pantchev (2012b). They include the following examinations: routine laboratory tests (haematology, clinical chemistry, urine analysis), tests for other infectious agents (serology, PCR and antigen detection if necessary) and immune-mediated diseases (rheumatoid factor, antinuclear antibodies or Coombs test), x-rays of one or more limbs, joint tap for cytology and culture (up to 76,000 cells/ microlitre (normal<3000), up to $97 \%$ of cells neutrophils (Straubinger et al. 1998), increased protein concentration and turbidity are compatible with Lyme arthritis), tumour detection (thoracic x-ray, abdominal ultrasound, fine needle aspiration of lymph nodes and bone marrow cytology). The procedure for a Borrelia-positive dog is shown in Fig. 9. Additionally, Susta et al. (2012) found an inflamed or borderline synovial aspirate (100-cell differential count; inflamed if $\geq 20 \%$ neutrophils, borderline at $8-19 \%$ and non-inflamed when $<8 \%$ neutrophils) in $47 \%(8 / 17)$ of experimentally infected dogs. Moreover, post-mortem histopathological scoring of the synovial membrane (elbows and stifles), using a proposed grading scheme, was a reliable method for discriminating infected and non-infected animals $(88.2 \%$ sensitivity and $100 \%$ specificity). 
As Fig. 9 shows, it is important to test Borreliapositive dogs for proteinuria. An association is assumed between Borrelia infection and renal disease, termed "Lyme-associated protein-losing nephropathy" (PLN) or "Lyme nephritis" (LN). In single studies, breeds commonly affected included labrador retriever, golden retriever and sheltie. In one study, 17 out of 20 Bernese mountain dogs were seropositive (IgG-IFA), but, because the immunohistochemical studies were negative, a familial nephropathy was assumed (Minkus et al. 1994). Dogs with suspected LN were younger (53\% $\leq 5$ years with an average of 5.6 years) than dogs with similar diseases of different genesis ( 7.1 years for glomerulonephritis and 7.8 years for amyloidosis). There was no gender predisposition, and the animals were usually presented in summer and autumn with acute or chronic kidney disease accompanied by anorexia, vomitus, thromboembolism, hypertension, oedema, oliguria or pigmenturia (Dambach et al. 1997; Littman et al. 2006; Chou et al. 2006; Goldstein et al. 2013; Littman 2013). Clinical signs associated with the central nervous system (CNS) can also occur in association with nephropathy, for example as a consequence of vasculitis, hypertension, thromboembolism and uraemic encephalopathy. Laboratory abnormalities include non-regenerative anaemia, thrombocytopenia, hypoalbuminaemia, azotaemia, hyperphosphataemia and proteinuria, with a urine specific gravity below 1.022. In contrast to leptospirosis, LN is not the consequence of direct renal invasion of spirochaetes, but it is regarded as an immune-mediated disease. It is described as an infection-related sterile immune-complex glomerulonephritis with deposition of Borrelia-specific antigen-antibody complexes. This renal form is frequently IHCpositive for antigen but PCR-negative for DNA, with a p.i. disease incidence of $1.85 \%$ (Dambach et al. 1997; Chou et al. 2006; Hovius 2013; Littman 2013). In regard to histopathology, $\mathrm{LN}$ is presented as an immune-mediated membranoproliferative glomerulonephritis ("MPGN"), combined with lympho-plasmocytic interstitial infiltrates and tubulonephrosis. In one study, 27 out of 32 dogs (84\%) with glomerulonephritis diagnosed by histology showed positive IHC staining of renal tissues (rabbit-derived polyclonal antiserum directed against a whole-cell preparation of $B$. burgdorferi strain B31 was used; Chou et al. 2006). Currently, it is not well understood whether LN is underrecognized, whether mild or early forms exist, and whether it responds to early intervention. According to Littman (2013), it may be under-diagnosed, especially in the case of mild or early forms in Borrelia-positive but asymptomatic dogs, or in positive symptomatic dogs not tested for proteinuria. On the other hand, LN may be over-diagnosed where a proteinuria in Borrelia-positive dogs is merely coincidental, due to urinary tract disease such as pyelonephritis, leptospirosis or a PLN of different genesis (infectious, genetic, systemic lupus erythematosus, neoplasia or haemolytic uraemic syndrome). There is also a need for further clarification as to whether non-Borrelia spp.-specific immune complex deposition also occurs in cases of LN. One study found that $16 \%$ of suspected LN cases did not show a positive IHC response to immune complexes (Chou et al. 2006). A further open question remains as to whether the specific immune complexes cause LN or are only passively deposited there (or not adequately eliminated) due to hostpathogen factors such as the Borrelia spp. strain, genetic podocytopathies or immunopathological changes (Littman 2013). The latter hypothesis is supported by a recent case in which the authors considered LN as the expression of a breed-related (soft-coated wheaten terrier/SCWT) PLN, in which the Borrelia spp. antigens may have triggered the development of the initial immune complexes (Horney and Stojanovic 2013). This is additionally corroborated by a recent human case of Lymeassociated glomerulonephritis with a probable underlying IgA nephropathy at baseline (chronic ethanolic hepatitis with polyclonal increase of IgA; Rolla et al. 2013).

There are currently no officially recognized tests able to predict which dogs might be susceptible to 


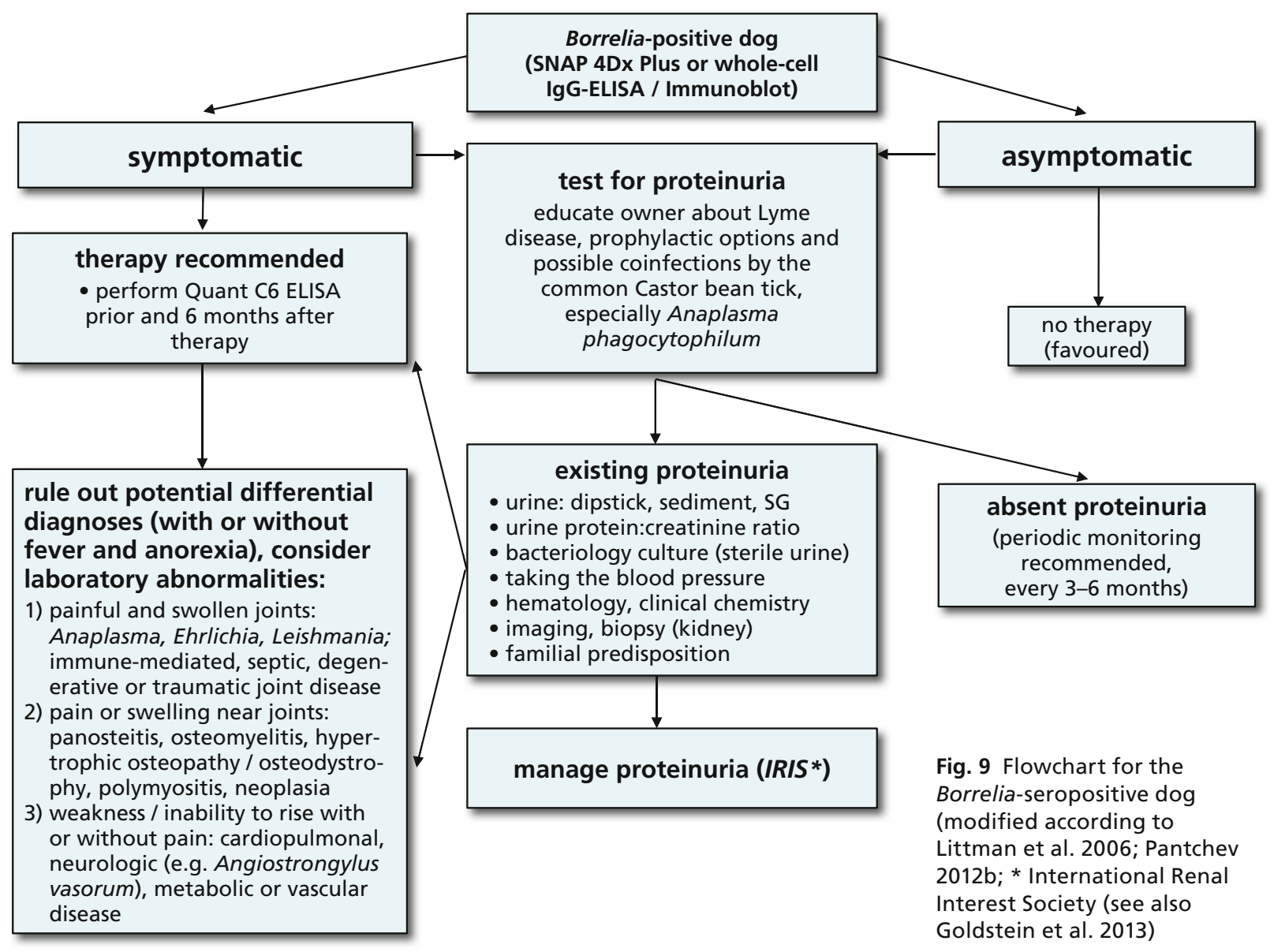

LN, although some attempts to fill this gap were made in the past. Despite monthly tick prophylaxis, a study group of dogs showed $18.7 \%$ seropositivity using a $\mathrm{C} 6$-antibody-based test $\left(\mathrm{SNAP}^{\circledR}\right.$ $\left.3 \mathrm{Dx}^{\circledR}\right)$, but no correlation with microalbuminuria (present in 6.1\%; E.R.D. HealthScreen Urine Test) was found (Goldstein et al. 2007). This group consisted of young, clinically normal labradors and golden retrievers (median age 1.5 years; $n=268$ ), in a Lyme-endemic region in the USA. However, this study only compared qualitative $\mathrm{C} 6$ seropositivity with microalbuminuria, and then only in young dogs. In experimentally infected dogs, Susta et al. (2012) found an urine protein: creatinine ratio (UPC) 120 days p.i. that was elevated, compared with the ratio 90 days p.i. in 8 out of 17 animals. However, the difference was not statistically significant, the chosen cut-off of $<1$ appears to be too high (see below) and the method used to determine the UPC was not stated. In a naturally infected, 6-year-old SCWT in Canada, mentioned above, which was initially presented with lameness, peripheral lymphadenopathy, anorexia and weakness, ACAC of $176 \mathrm{U} / \mathrm{ml}$ and an elevated UPC (8.58) were found (Horney and Stojanovic 2013). In addition to supportive treatment for a suspected familial, breed-related PLN, doxycycline was administered ( $5 \mathrm{mg} / \mathrm{kg}$ b.i.d. for 4 weeks). ACAC subsequently decreased to $41 \mathrm{U} / \mathrm{ml}$ and the UPC to 1.73. Results of the latter study indicate that ACAC could represent a test able to predict which dogs are predisposed for development of LN or which could facilitate the diagnosis of LN. The correlation between (high) ACAC and proteinuria in dogs (without preselection based on age) has not been previously investigated. 
Recently, we evaluated 103 canine samples: single samples of serum and urine provided by European veterinarians with the request for Quant C6 ELISA (serum; performed according Levy et al. 2008) und UPC (urine; for methods see Table 4) during 2009-2013 (Pantchev 2014). Submissions were received from Germany and other European countries ( $n=71$ from Germany, $n=7$ from Austria, $n=1$ from the Czech Republic, $n=4$ from Denmark, $\mathrm{n}=1$ from France, $\mathrm{n}=4$ from Finland, $\mathrm{n}=2$ from Luxembourg, $\mathrm{n}=6$ from the Netherlands, $n=2$ from Norway and $n=5$ from Sweden). Data were obtained by testing serum and urine in parallel. Subsequently, samples were divided into 3 groups on the basis of their ACAC: $<10$, $10-30$ and $>30 \mathrm{U} / \mathrm{ml}$ and a statistical comparison (CS) with their UPC value ( $>=0.6$ as a cut-off) was conducted. In total, 55 samples had an UPC greater than or equal to 0.6 (53.4\%; 95\% CI: $43.3-63.3$ ) and $46 \mathrm{dogs}$ showed an ACAC above $30 \mathrm{U} / \mathrm{ml}$ (44.7\%; 95\% CI: 34.9-54.8). Dogs with ACAC in the moderate-to-high range (over $30 \mathrm{U} / \mathrm{ml}$; group 3) also showed a statistically significantly higher probability of increased UPC (greater than or equal to 0.6 according to IRIS criteria) in urine samples compared to dogs with ACAC in the low (10-30 U/ $\mathrm{ml}$; group 2) and negative to very low range (under $10 \mathrm{U} / \mathrm{ml}$; group 1; Table 4).

Table 4 Correlation of anti-C6 antibody concentration (Lyme Quant C6 ELISA in Units/ml) and proteinuria (urine protein:creatinine ratio/UPC) based on 103 canine serum and urine samples tested in parallel from the years 2009-2013.

\begin{tabular}{|c|c|c|c|c|}
\hline Group & Quant C6 Units/ml* & anti-C6 antibody level & UPC $>=0.6 * *$ & $\%$ and $95 \% \mathrm{Cl}^{* * *}$ \\
\hline 1 & $<10$ & $\begin{array}{l}\text { negative to very low } \\
\text { positive }\end{array}$ & $15 / 39$ & $38.5 ; 23.3-55.4$ \\
\hline 2 & $10-30$ & low & $5 / 18$ & $27.8 ; 9.7-53.6$ \\
\hline 3 & $>30$ & moderate to high & $35 / 46$ & $76.1 ; 61.2-87.5$ \\
\hline \multicolumn{5}{|c|}{ * allocation according to Levy et al. 2008} \\
\hline \multicolumn{5}{|c|}{$\begin{array}{l}\text { ** cutoff according to Goldstein et al. } 2013 \text { and www.iris-kidney.com; methods in brief: } \\
\text { creatinine determination in mg/dl by means of the Jaffe method (blank corrected, kinetic and photometric), } \\
\text { determination of protein in mg/dl, turbidimetric }(505 \mathrm{~nm}) \text { after the addition of benzethonium chloride }\end{array}$} \\
\hline \multicolumn{5}{|c|}{$\begin{array}{l}* * * \text { statistical significance of increased UPC with regard to anti-C6 antibody concentration (chi-square test; } p<0.05 \text { ) } \\
\text { Group } 1 \text { versus 2: } p=0.432 ; \text { not significant } \\
\text { Group } 1 \text { versus 3: } p<0.001 \text { significant } \\
\text { Group } 2 \text { versus 3: } p<0.001 \text { significant } \\
\text { Groups } 1 \text { and } 2(20 / 57 ; 35.1 \%, 95 \% \mathrm{Cl}: 22.9-48.9) \text { versus } 3(35 / 46): p<0.001 \text { significant }\end{array}$} \\
\hline
\end{tabular}

Table 5 Total submissions for the Lyme Quant C6 ELISA from the years 2009-2013 ( $n=15,757$ canine serum samples) and fractions with an anti-C6 antibody concentration over $30 \mathrm{U} / \mathrm{ml}$.

\begin{tabular}{|c|c|c|c|c|c|}
\hline Year & Total samples & Samples over $30 \mathrm{U} / \mathrm{ml}$ & percentage & $95 \% \mathrm{Cl}$ & significance* \\
\hline 2009 & 2944 & 564 & 19.2 & $17.8-20.6$ & $\downarrow ; p<0.001$ \\
\hline 2010 & 2882 & 605 & 21.0 & $19.5-22.5$ & $\downarrow ; p<0.001$ \\
\hline 2011 & 3288 & 753 & 22.9 & $21.5-24.4$ & $n s ; p=0.111$ \\
\hline 2012 & 3292 & 911 & 27.7 & $26.2-29.2$ & $\uparrow ; p<0.001$ \\
\hline 2013 & 3351 & 981 & 29.3 & $27.7-30.8$ & $\uparrow ; p<0.001$ \\
\hline $2009-2013$ & 15757 & 3814 & 24.2 & $23.5-24.9$ & - \\
\hline
\end{tabular}


On the other hand, groups 1 and 2 showed no difference with regard to increased UPC (Table 4). Dogs from group 3 with ACAC over $30 \mathrm{U} / \mathrm{ml}$ (median $137 \mathrm{U} / \mathrm{ml}$ ) and elevated UPC (median 6.5) were also significantly younger (average age of 5.5 years, median 5 years) compared to dogs from groups 1 and 2 with an elevated UPC (median 1.4), but ACAC was less than or equal to $30 \mathrm{U} / \mathrm{ml}$ (average age of 7.9 , median 9 years). This corroborates the above mentioned results by Dambach et al. (1997) for LN based on 49 canine cases with renal lesions putatively associated with $B$. burgdorferi infection. This might indicate that proteinuria in dogs with C6 antibody levels lower than or equal to $30 \mathrm{U} / \mathrm{ml}$ occurs coincidentally and might have another genesis as proposed by Dambach et al. (1997). Within Group 3 (>30 U/ml) 11 of $46 \operatorname{dogs}(23.9 \%$; 95\% CI: 12.5-38.8) with UPC below 0.6 also showed a lower median ACAC (94 versus $137 \mathrm{U} / \mathrm{ml}$ ); only 4 of these 11 dogs (36.4\%; 95\% CI: 9.8-69.9) showed ACAC $>100 \mathrm{U} / \mathrm{ml}$, compared with 21 of $35 \mathrm{dogs}$ (60\%; $95 \%$ CI: 42.1-76.2) with ACAC $>100 \mathrm{U} / \mathrm{ml}$ and increased UPC; however, this difference was not significant $(p=0.435)$. Another study in dogs showed a median UPC of 5.7 (0.47 to 43.4) for glomerulonephritis, 22.5 (11.2 to 46.6 ) for amyloidosis and 2.9 (1.5 to 10.5) for chronic interstitial nephritis (CIN; Center et al. 1985). So it is suggested that UPC in dogs is usually less than 5 with CIN, whereas primary glomerular disease is associated with UPC above 5 . This corresponds well to the median value of 6.5 for UPC found in our study for dogs in group 3 (see above).

Our data suggest that ACAC, in particular a concentration over $30 \mathrm{U} / \mathrm{ml}$, in combination with a corresponding history can serve as a marker of $\mathrm{LN}$ in dogs. Further studies with a larger number of samples are needed to show whether an ACAC above $100 \mathrm{U} / \mathrm{ml}$ can be regarded as high and may indicate an early form of LN in dogs without proteinuria. The correlation between high antibody levels and disease has generally been disputed (e.g. Littman 2013). A study in which cases of high ACAC in asymptomatic dogs were found (Levy et al. 2008), might further support this hypothesis. However, no haematology, clinical chemistry or urine analyses were performed by Levy et al. (2008). While dogs were clearly described as asymptomatic, they were not defined as healthy as suggested by Dantas-Torres and Otranto (2014b). For example, it is not known whether these dogs with initial ACAC in the moderate-to-high groups (Levy et al. 2008) may have had proteinuria. Whether ACAC also correlates with the level of specific immune complexes (which were higher in dogs with clinical signs of infection), as proposed by Goldstein and Atwater (2006), should be a topic for further studies.

In addition to the above retrospective study comparing ACAC with UPC in a dog collective (Table 4), we evaluated data from 15,757 canine serum samples submitted by veterinarians for a Lyme Quant C6 ELISA only (for methods see above) in 2009 to 2013 (previously unpublished data). The largest fraction of animals was the group under $10 \mathrm{U} / \mathrm{ml}$ ( $\mathrm{n}=9,669 ; 61.4 \% ; 95 \%$ CI: 60.6-62.1). The next group with $10-30 \mathrm{U} / \mathrm{ml}$ contained $14.4 \%$ of the cases $(n=2,274 ; 95 \% \mathrm{CI}: 13.9-15)$ and the third group with ACAC $>30 \mathrm{U} / \mathrm{ml}$ contained $24.2 \%$ $(\mathrm{n}=3,814 ; 95 \%$ CI: 23.5-24.9). The differences in group 1 and 3 with ACAC under $10 \mathrm{U} / \mathrm{ml}$ and over $30 \mathrm{U} / \mathrm{ml}$ were statistically significant compared with the dogs with suspected LN (parallel testing for ACAC in serum and UPC in urine; Table 4) $(p=0.003$ and $p<0.001$, respectively). Interestingly, the percentage of dogs with a request for Lyme Quant C6 ELISA and with ACAC over $30 \mathrm{U} / \mathrm{ml}$ has increased continuously and significantly over the years, from $19.2 \%$ (95\% CI: $17.8-20.6$ ) in 2009 to $29.3 \%$ (95\% CI: $27.7-30.8$ ) in 2013 (Table 5). It is not clear yet what effects might be responsible for this significant increase in the proportion of samples over $30 \mathrm{U} / \mathrm{ml}$. Possible reasons include better preselection by the attending veterinarian of dogs matching the clinical picture in terms of age, breed, etc. Other reasons might be geographical (region-specific) influences or vector-related influences (other Borrelia spp. strains with different plasmid content and virulence in the field). New 


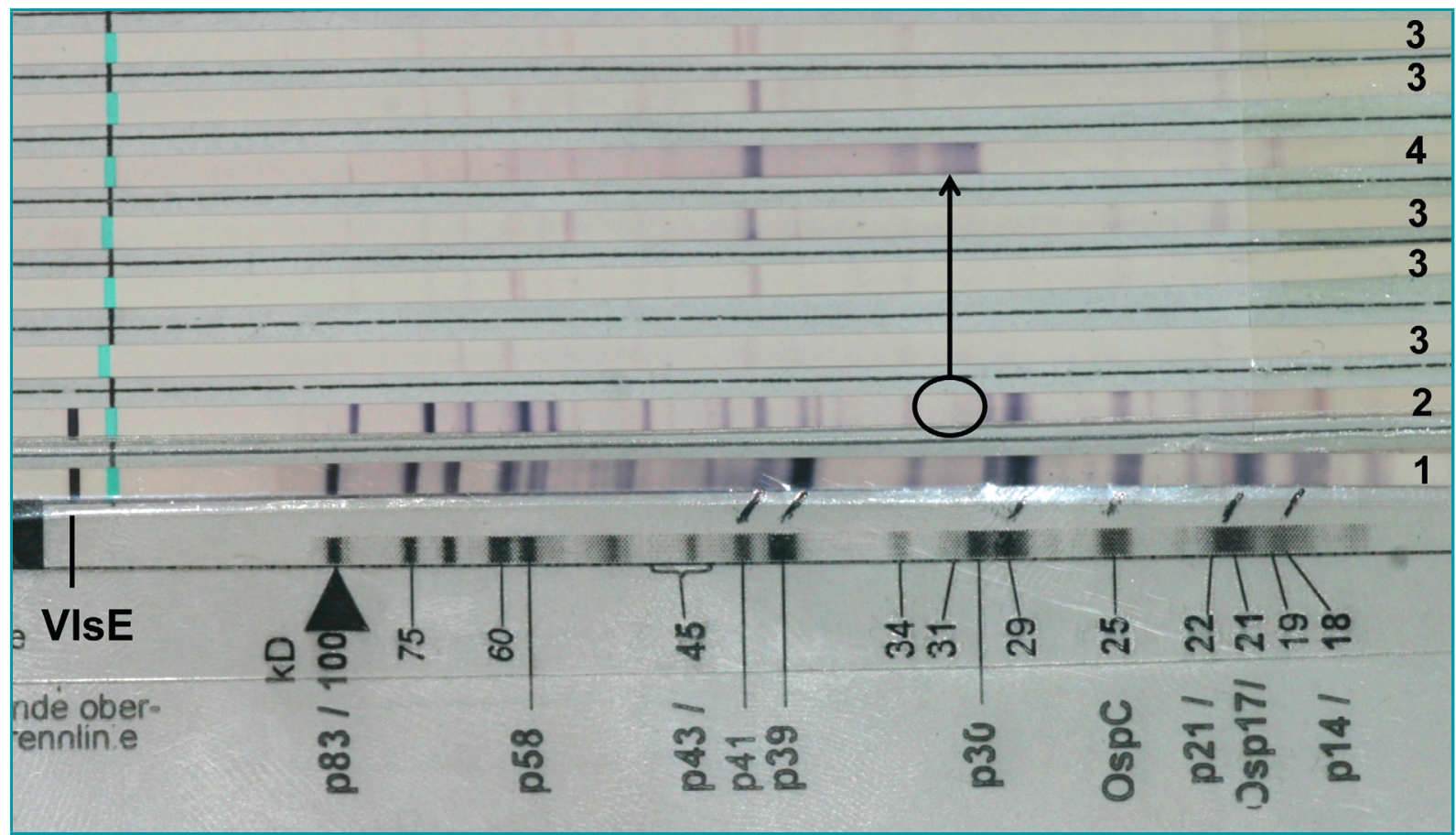

Fig. 10 Immunoblot of a dog with suspected Lyme nephritis (LN); 1: positive control serum with (below) a protein marker with molecular weight of the bands in $\mathrm{kDa}$; 2 : suspected LN case: typical band pattern of an infected, unvaccinated dog (e.g. VIsE, p83/100, p58, p39, p29/OspD and OspC protein bands present, but OspA (31 kDa; predomimant signal associated with vaccination) absent (oval); 3 : negative samples (some only reactive for the 41-kDa flagellin band); 4: prominent OspA band of a vaccinated, non-infected dog (arrow) (Borrelia "MiQ" + VIsE ViraBlot/Viramed; secondary antibodies: AP-conjugated goat anti-dog $\lg G(\mathrm{H}+\mathrm{L})-\mathrm{KPL})$.

studies differentiating Borrelia spp. by means of multilocus sequence typing (MLST) indicate that different $B b$ ss strains have different dissemination potentials within the organism, pointing to different pathogenic properties (Hanincova et al., 2013). Other relevant effects might include co-infections or co-diseases and a shift in prophylactic methods used against ticks and in the frequency or type of vaccinations (see below).

In dogs with suspected LN, the importance of testing the band pattern in immunoblot assays is also highlighted (Littman 2013). In one suspected case tested in our laboratory (hunting crossbreed dog, 5 years old; previously unpublished data), the immunoblot test showed a field infection with almost all specific bands reacting positively, including VlsE, but without the classic vaccine band OspA (Fig. 10). The dog also showed severe proteinuria (UPC of 17.8), hypoalbuminaemia, azotaemia, anaemia, and a high ACAC of $430 \mathrm{U} / \mathrm{ml}$. In comparison, the total IgG level, measured using a non-C6/VlsE-based whole-cell ELISA (B. burgdorferi veterinary ELISA, Virotech), was relatively low at 35.6 units (positive cut-off: 12 units). X-ray of the kidneys revealed no abnormalities; a biopsy was not performed. No other causes were found for the renal damage, following negative tests for Leptospira-specific antibodies (microagglutination test; MAT), L. infantum-specific antibodies (ELISA; Wolf et al. 2014), A. phagocytophilum-specific and E. canis-specific antibodies (IFA and SNAP ${ }^{\circledR} 4 \mathrm{Dx}^{\circledR}$; Dyachenko et al. 2012) and antinuclear antibody (IFA, Kallestad ${ }^{\text {TM }}$ HEp-2 cells, Biorad). A familial predisposition was ruled out. The dog was presented at the veterinary practice in August, showing fever, fatigue, vomitus and polydipsia. 
Table 6 Three cases of canine granulocytic anaplasmosis in dogs presented to veterinarians in April (modified according to Pantchev 2010a; methods according to Dyachenko et al. 2012); ALKP: Alkaline phosphatase, IFA (indirect immunofluorescence assay), ALT: alanine aminotransferase, CRP: C-reactive protein, Ct value (= cycle threshold: lower values represent higher amount of pathogen DNA).

\begin{tabular}{|c|c|c|c|}
\hline & Dog from Germany & Dog from the Netherlands & Dog from Austria \\
\hline Age & 6 years & 10 years & 11 years \\
\hline Clinical findings & $\begin{array}{c}41.3-41.8^{\circ} \mathrm{C} \text {, peracute } \\
\text { disease accompanied by } \\
\text { reluctance to move, } \\
\text { lethargy, anorexia, pale } \\
\text { mucous membranes }\end{array}$ & $\begin{array}{c}40.9^{\circ} \mathrm{C} \text {, lethargy, upper } \\
\text { abdominal pain }\end{array}$ & $\begin{array}{l}\text { lethargy, anorexia, pale } \\
\text { mucous membranes, } \\
\text { severe diarrhoea }\end{array}$ \\
\hline \multicolumn{4}{|c|}{ Laboratory } \\
\hline CRP (0-9.7 mg/l) & $\uparrow 48.8$ & $\uparrow 57.0$ & $\uparrow 63.8$ \\
\hline $\begin{array}{l}\text { Thrombocytes } \\
(150-500 \mathrm{G} / \mathrm{l})\end{array}$ & $\downarrow 50$ & unevaluable & $\downarrow 118$ \\
\hline $\begin{array}{l}\text { Lymphocytes } \\
\text { (1000-4000/ul) }\end{array}$ & $\downarrow 656$ & $\downarrow 748$ & $\downarrow 284$ \\
\hline $\begin{array}{l}\text { Monocytes } \\
(0-500 / \text { ul })\end{array}$ & $\uparrow 1031$ & $\uparrow 534$ & $\uparrow 663$ \\
\hline $\begin{array}{l}\text { Albumin } \\
(32-47 \mathrm{~g} / \mathrm{l})\end{array}$ & $\downarrow 31$ & $\downarrow 30$ & $\downarrow 23.8$ \\
\hline $\operatorname{ALKP}(<81 \mathrm{U} / \mathrm{I})$ & $\uparrow 436$ & $\rightarrow 65$ & $\uparrow 115$ \\
\hline ALT (5-125 U/I) & $\rightarrow 65.5$ & $\uparrow 277$ & $\rightarrow 50.4$ \\
\hline \multicolumn{4}{|l|}{ Blood smear } \\
\hline Real-time PCR & positive (Ct value: 16 ) & positive (Ct value: 26 ) & positive (Ct value: 14$)$ \\
\hline Serology (IFA) & negative $(<1: 50)$ & $1: 100$ ( 2 weeks later $1: 3200)$ & negative $(<1: 50)$ \\
\hline
\end{tabular}

\section{Canine granulocytic anaplasmosis (CAG)}

It is essential to take into consideration co-infections with Borrelia in the diagnostic workflow of CAG. Studies show that dogs co-infected with A. phagocytophilum and Borrelia spp. run twice the risk of developing disease with clinical signs such as lameness, fever, lethargy, joint pain (swelling) and anorexia compared to with single infections with either pathogen (Beall et al. 2008). The concurrent presence of an intracellular (Anaplasma spp.) and extracellular (Borrelia spp.) infection may lead to an adverse immunological interaction during the infection course (Krupka et al. 2007). In the majority of dogs, the clinical signs of CAG are non-specific and confined to the acute phase of the infection (Diniz and Breitschwerdt 2012). Thus, "CAG" pose a diagnostic challenge. The criteria for diagnosing this disease according to the Centers for Disease Control and Prevention (modified according to Kohn et al. 2008) include tick contact or blood transfusion with clinical symptoms or laboratory abnormalities, positive PCR and/or morulae in neutrophils and a four-fold increase in antibody levels within four weeks. There appears to be no breed-related predisposition, although there may be a predisposition based on age. For example, in the USA $35.3 \%$ of affected dogs were between 8 and 10 years old, $58.8 \%$ were at least 6 years old and 
Table 7 Two ways to detect a pathogen (serology versus PCR): what are the differences?

\begin{tabular}{|l|l|}
\hline \multicolumn{1}{|c|}{ Serology } & \multicolumn{1}{|c|}{ PCR } \\
\hline $\begin{array}{l}\text { Detects the immunological antibody response of the } \\
\text { infected host }\end{array}$ & Detects nucleic acid of the infectious agent \\
\hline Antibodies persist over time - suitable for screening & $\begin{array}{l}\text { The infectious agent (or its DNA) must be present in the } \\
\text { sample - suitable in the acute phase of the disease }\end{array}$ \\
\hline $\begin{array}{l}\text { The immune response takes time, so clinical symptoms } \\
\text { may appear before a measurable antibody response }\end{array}$ & $\begin{array}{l}\text { A positive result indicates the presence of the agent, but } \\
\text { a negative result does not necessarily rule out infection }\end{array}$ \\
\hline
\end{tabular}

only $11.7 \%$ were under oder equal the age of 1 year (Greig et al. 1996). In a Swedish study, 28.6\% of the dogs were over the age of 9 and $0 \%$ under the age of 1 (Egenvall et al. 1997). The pattern is similar in humans, as patients are commonly in the 50 - to 60 -year age range, with children only rarely affected (Diniz and Breitschwerdt 2012). A possible explanation might be that repeated reinfection is necessary (hence older dogs), or a fully developed immune system is required, because Anaplasma spp. impact on various immunological processes in order to survive (Egenwall et al. 1997; Carrade et al. 2009; Woldehiwet 2010). There appears to be a degree of seasonality, in parallel with the emergence of ticks (approximately from April to September; Kohn et al. 2008; Carrade et al. 2009). The characteristic clinicopathological abnormalities and the options for specific diagnosis are illustrated in the form of a diagram in Table 6 on the basis of three case examples (one each from Germany, the Netherlands and Austria).

Among the clinicopathological abnormalities, thrombocytopenia is the most important alteration in more than $80 \%$ of cases (Greig et al. 1996; Kohn et al. 2008; Carrade et al. 2009; Diniz and Breitschwerdt 2012). In one study, over half of the dogs reacted positively in a platelet-bound antibody test (Kohn et al. 2008). Other important abnormalities are lymphopenia (approx. 50\%), anaemia (approx. 60\%; mild to moderate, non-regenerative and normochromic), occasionally hypoalbuminaemia (mild to moderate) and an increase in alkaline phosphatase and possibly other liver enzymes such as alanine aminotransferase (Table 6). Proteinuria has been also described. A relatively new but definitely additional promising test appears to be the measurement of C-reactive protein (CRP), which can increase by up to tenfold in the acute phase of the disease (Pantchev 2010a). CRP levels might also be useful in monitoring the success of treatment, as they are not influenced by the administration of glucocorticoids, for example (KjelgaardHansen et al. 2006). Because of the seronegativity of some clinical cases (see Table 6), a confirmed diagnosis of CAG, from a single diagnostic test, may not be sufficient. Following experimental infection (with various isolates; i.v. with autologous infected neutrophils, not with ticks), dogs tested positive by PCR (blood) from 2 days p.i., seroconversion occurred after 10-14 days p.i. using IFA, and morulae were visible in blood smears between days 10 and 11 p.i. (Scorpio et al. 2011). This shows that the results of diagnostic tests will vary according to the time point post-infection (Fig. 11) and that concurrent use of serology and PCR will therefore increase the likelihood of an accurate diagnosis (Table 7).

The options for specific diagnosis in veterinary practice are limited to the detection of intracytoplasmatic inclusions (morulae) in neutrophils (in stained blood smears) during the acute infection phase and to indirect serological procedures using the $\mathrm{SNAP}^{\circledR} 4 \mathrm{Dx}^{\circledR}$ rapid test (currently available as $\mathrm{SNAP}^{\circledR} 4 \mathrm{Dx}^{\circledR}$ Plus for the additional detection of antibodies to Ehrlichia ewingii). This assay detects antibodies (qualitatively; $17-30$ days p.i.; Scorpio 


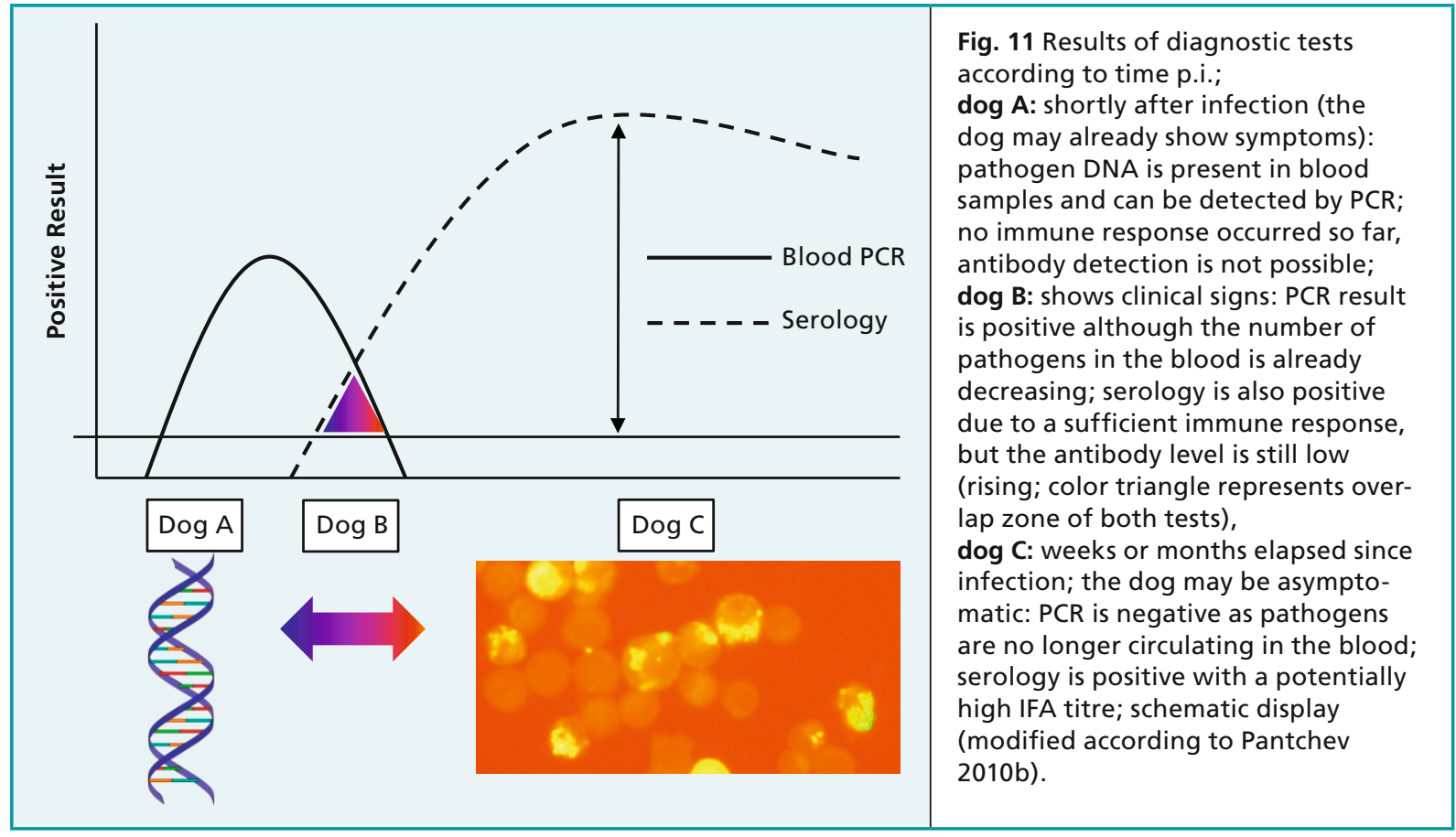

et al. 2011) to a major surface protein (p44/MSP2) of A. phagocytophilum. Antibodies to Anaplasma platys are also detected, as was shown in a experimental study (Gaunt et al. 2010). An advantage of this test is the option of simultaneously detecting antibodies to the C6 peptide of $B b s l$, and for dogs with a history of travel in endemic regions, antibodies to $E$. canis and heartworm antigen. Further diagnostic options in reference laboratories include IFA for serology and specific real-time PCR tests for molecular detection. IFA allows semi-quantitative determination of antibody levels in blood (titre determination). This is useful in order to observe fluctuations (increase or decrease) in antibody response. Seroconversion occurs two to five days after the initial appearance of morulae in peripheral blood (see above; Scorpio et al. 2011). Titres then increase within 2 to 3 weeks (see also Table 6; Scorpio et al. 2011) and decrease between 4 to 8 months after the detection of inclusions within a blood smear and treatment with doxycycline (Egenwall et al. 1997). An increase in titres in some dogs in the Swedish study after the next (tick) season can most probably be explained by asymptomatic re-infections. A disadvantage of the A.phagocytophilum IFA compared with tests using specific peptides (e.g. $\mathrm{SNAP}^{\circledR} 4 \mathrm{Dx}^{\circledR}$; Chandrashekar et al. 2010 ) is possible cross-reactivity with $E$. canis antibodies. The strength of the cross-reactivity of such sera when tested with $A$. phagocytophilum antigen increases with the duration of the $E$. canis infection and the $E$. canis antibody titre (Harrus et al. 2012). For example, in dogs infected experimentally with $E$. canis, no cross-reactivity with $A$. phagocytophilum antigens was observed in the acute phase; however, cross-reactive antibodies were first detected on day 55 p.i. and were then found in all dogs by day 150 p.i. (Harrus and Waner 2011). The PCR for direct detection of pathogen DNA in blood is more sensitive than the microscopic scanning of stained blood smears, demonstrated with experimentally infected dogs. The dogs tested positive for Anaplasma spp. DNA, 6 to 8 days before morulae could be detected in peripheral blood (Scorpio et al. 2011). The authors also showed that in the canine model the bacterial load (quantitative real-time PCR) correlated with platelet decline, observed until the end of the study period (60 days p.i.). However, there 


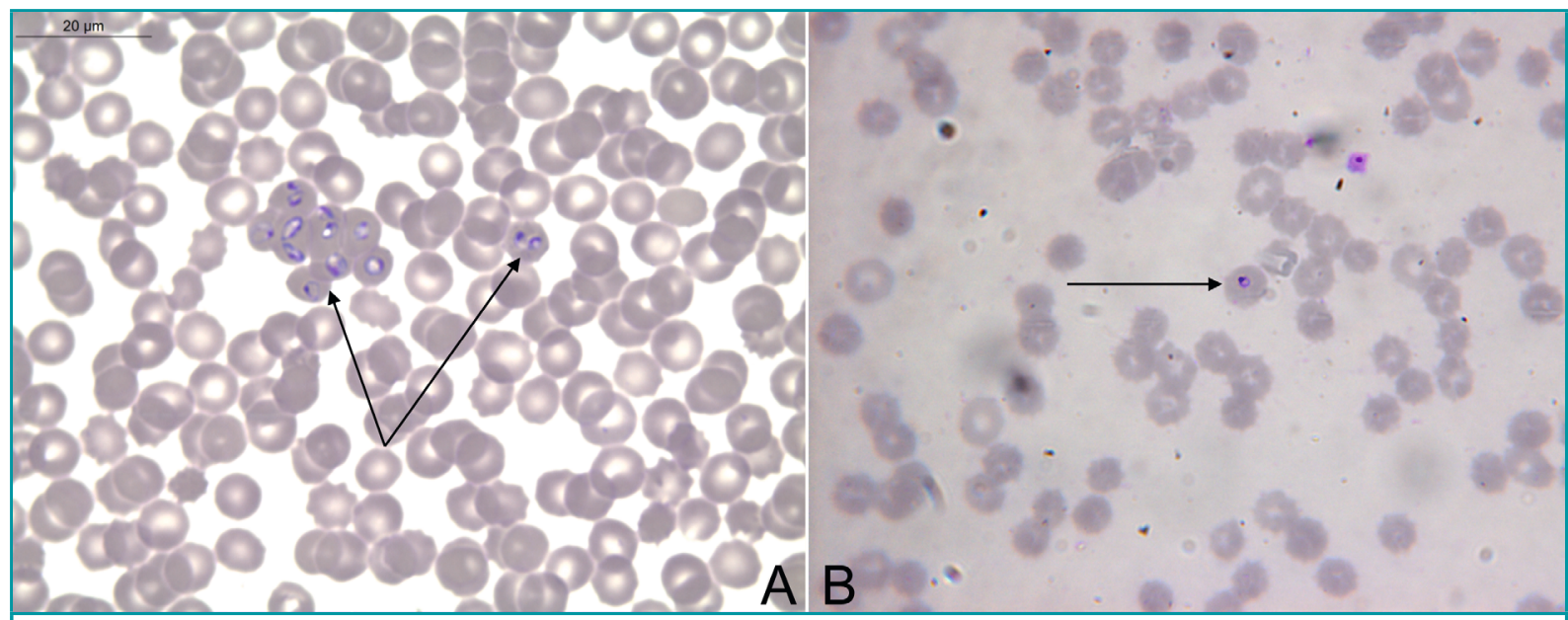

Fig. 12 A: large Babesia (arrows); in this case characterized as Babesia rossi by SSU rDNA amplification with subsequent sequencing according to Carret et al. (1999) in a stained blood smear from a dog imported from South Africa

B: atypical, smaller, rounded form of Babesia canis (arrow) characterized by SSU rDNA amplification and sequencing (see above); scale bar $=20 \mu \mathrm{m}$

were some differences based on the A.phagocytophilum strain and cell type used for i.v. infection. PCR allows the differentiation of A.phagocytophilum and A.platys (the latter is important in dogs with a history of travel to endemic regions; Dyachenko et al. 2012), which again can crossreact serologically (Gaunt et al. 2010). There have been recent reports of PCR-positive findings in skin biopsies from dogs with skin lesions of unknown origin and a histological picture of vasculitis (Berzina et al. 2014). The involvement of A. phagocytophilum in such cases and the interpretation of DNA detection in skin tissue require further clarification.

\section{Canine babesiosis}

For the diagnosis of canine babesiosis the following points should be considered (according to Pantchev 2012a): anamnesis including history of travel in endemic areas and tick infestation, blood transfusion or other possible non-vector-borne transmission routes (see above), clinical findings and laboratory abnormalities, direct pathogen detection in blood smears stained using Giemsa, Wright or Diff-Quik or DNA detection by PCR, and indirect pathogen detection by serology (ELISA, IFA). Typical laboratory findings, which differ depending on the Babesia species (see Tables 2 and 3), are haemolytic anaemia (initially non-regenerative, normocytic and normochromic, later regenerative, macrocytic and hypochromic), secondary immunohaemolytic anaemia with positive Coombs test, spherocytes, leukocytosis with a left shift in many cases, and thrombocytopenia and neutropenia. Further clinicopathological abnormalities are haemoglobinuria, bilirubinuria, bilirubinaemia and proteinuria (due to intravascular haemolysis), an increase in aspartate aminotransferase, alanine aminotransferase (hepatopathy) and azotaemia, and chronic hypoalbuminaemia (hepatopathy and glomerulopathy) (Ayoob et al. 2010; Birkenheuer 2012). The specific diagnostic options in veterinary practice during the acute phase are limited to stained blood smears, which allow differentiation between large (Fig. 12A) and small Babesia species. Capillary blood or buffy coat preparations are more suitable in many cases, because infected erythrocytes sequestrate in capillaries and Babesia tend to invade reticulocytes rather than mature erythrocytes (Irwin 2009; Ayoob et al. 2010; Ogo et al. 2011). Differentiation of large versus small forms is usually possible, except in rare cases of atypical 
B. canis stages which unexpectedly can take on a small, rounded form (Fig. 12B). In these cases, PCR is indicated to ensure reliable differentiation (see also Demeter et al. 2011). Small and large Babesia species should be clearly differentiated at diagnosis, because they require different treatment protocols (see below).

Further testing options in a reference laboratory include quantitative serology and PCR. Large Babesia (B. canis, B. vogeli and B. rossi) are known to cross-react with each other's antigen using IFA, even though they produce stronger IFA reactions in homologous systems (e.g. B. canis antigen with $B$. canis-infected dog; Uilenberg et al. 1989; Jongejan et al. 2011). Beyond that, Babesia can also cross-react at genus level (e.g. B. canis and $B$. gibsoni), irrespective of the test used (IFA or ELISA), if the test uses whole-cell antigen (Belton 2003; Birkenheuer et al. 2003; Ogo et al. 2011; own observations). Within the above-mentioned wholecell $B$. canis ELISA, cross-reaction with $B$. vogeli has already been shown (Dyachenko et al. 2012). Furthermore, seven out of nine molecularly confirmed B.gibsoni canine samples from Hungary, Sri Lanka, Germany and Czech Republic (seven of them were fighting dogs; real-time PCR according to Dyachenko et al. 2012) also showed clearly positive reactions within the same B. canis ELISA (own unpublished observations). Additionally, three canine samples from mixed-breed dogs from Argentina (provided by Diego Fernando Eiras, Universidad Nacional de La Plata) suspected of having $R$. vitalii infections (merozoite stages in erythrocytes and leukocytes; see Eiras et al. 2014) reacted clearly positively as well (so far unpublished data). $R$. vitalii represents a large piroplasm occurring in Brazil and Argentina, and is proposed as the causative agent of canine rangeliosis (known as "bloody ears" disease; Eiras et al. 2014; see also Table 2). In general, serology cannot distinguish between animals with an acute or chronic infection (Irwin 2009; Ogo et al. 2011). Specific antibodies were detected on day 14 p.i. in 5 out of 7 dogs experimentally infested with D. reticulatus and infected with
B. canis, and all animals seroconverted on days 21 and 28 p.i. (with titres from 1:160 to $\geq 1: 2560$; Jongejan et al. 2011). Similar results were achieved after sporozoite-induced subcutaneously infection with a French B. canis isolate (seroconversion at 13 to 20 days p.i.; Uilenberg et al. 1981). Following experimental parenteral infection with $B$.vogeli in dogs, seroconversion occurred seven days p.i., with increasing titres from 14 to 21 days p.i. and maximum titres of $1: 1280$ to $1: 5120$ on $48-55$ days p.i.. The antibody titres then decreased slightly until day 160 (approximately 2 dilution levels) to 1:640-1:1280 (Brandao et al. 2003). The serology results for the treated group in the latter study (treatment with imidocarb, $7 \mathrm{mg} / \mathrm{kg}$ on days 15 and 27 p.i.) were significantly different, as titres were lower and decreased faster (from day 34 p.i. onwards). Capillary parasitaemia accompanied by fever was observed from 2 days p.i. until 41 days p.i. (intermittently during this time; Brandao et al. 2003). The disappearance of Babesia from the blood approximately correlated with the maximum antibody titres. Interestingly, antibody titres $\geq 1: 320$ showed a protective effect. In the latter experimental study parasitaemia had been observed 2 days p.i., which is earlier compared to the typical case in natural (tick-borne) infections of 6 to 20 days p.i. (Brandao et al. 2003). This time lag may be due to the fact that, in the study cited, the dogs were inoculated with erythrocytes containing merozoites, while in natural settings the sporozoites are the initial stages introduced by the ticks. After sporozoite-induced infection (subcutaneously with a French $B$. canis isolate) the prepatent period (blood smear from ear veins) was 5-7 days, and it was slightly shorter than the incubation period for fever (6-8 days; Uilenberg et al. 1981). The advantages of serology are the diagnosis of cases with low-level or intermittent parasitaemia (Uilenberg et al. 1981; Brandao et al. 2003) and of chronic infections (Irwin 2009). The limitations are cross-reactions (especially between different Babesia species, see above) and false-negative findings in young or immunosuppressed dogs, or early in 
the course of infection before seroconversion has occurred (Ayoob et al. 2010). This final limitation requires the testing of paired sera, with the second taken after an interval of 2 to 3 weeks. It should also be considered that dogs in B.canis-endemic regions may show high titres without showing clinical signs (Ayoob et al. 2010). Specific treatment with imidocarb and diminazene early in the course of infection (approx. 1 week p.i. after direct detection of B. canis in blood) prevented seroconversion in one out of eight dogs, as shown with an experimental model (Beugnet et al. 2014).

Another important aspect of Babesia diagnostics in dogs is the use of PCR tests. The detection limit of PCR protocols is given variously as 50 organisms per $\mathrm{ml}$ in one protocol and 9 per $\mu \mathrm{l}$ in another (reviewed by Irwin 2009). In one study, it was 1,300 times lower (better) than the detection limit of light microscopy (Birkenheuer et al. 2003). A single microscopic blood smear test, compared with PCR as the established gold standard, had a relative sensitivity of $38 \%$ and a relative specificity of over $99 \%$; there was moderate agreement between the results of the two methods (kappa $=0.54$; Globokar Vrhovec 2013). In the patient cohort tested by Globokar Vrhovec (2013; dogs living in Germany), microscopy detected Babesia significantly more frequently in animals that had stayed within Germany compared to animals with a history of travel or imported animals. These data agree with the serological data obtained for Germany (see above). It is possible that a larger proportion of the animals with a history of travel were tested preventively irrespective of symptoms, whereas the animals that had stayed within Germany were tested on the basis of clinical suspicion. Another major advantage of PCR is that, following a positive Babesia PCR result, differentiation of Babesia species can subsequently be performed by either species-specific real-time PCR (Dyachenko et al. 2012), or SSU rDNA amplification with subsequent sequencing (Beck et al. 2009). This is important in order to select an appropriate treatment, as large and small Babesia require different therapeutic approaches. The treatment of choice is imidocarb for large forms and a combination of atovaquone and azithromycin for B. gibsoni (Pantchev 2012a; Birkenheuer 2012). PCR itself has limitations, especially when no organisms are present in the blood (as in chronically infected animals), or if the parasitaemia is intermittent (Brandao et al. 2003; Irwin 2009). In these cases it is helpful to repeat PCR tests, or combine PCR with serology. In the above-mentioned study, which evaluated data from three different diagnostic procedures for B. canis (dogs living in Germany, 2004 to 2006), antibodies were detected (by IFA) in $11.5 \%(n=2,653)$ of dogs, parasitic stages were found in Giemsa-stained blood smears in $2.1 \%$ of samples $(n=9,966)$ and DNA was detected (by conventional PCR) in $3.3 \%$ of submitted blood samples ( $n=15,155$; Globokar Vrhovec 2013).

Another currently available tool used for detection of $B$. canis protein fractions in canine serum is the mass spectrometry (MALDI-TOF; Adaszek et al. 2014). Latter authors identified a protein fraction of $51-52 \mathrm{kDa}$ in samples of infected but not in control dogs. Further studies are necessary to estimate the sensitivity and specificity of this new technique for routine diagnostics with canine blood samples in comparison to currently applied species-specific real-time PCRs.

\section{Prophylaxis}

Prophylaxis is based on a range of different actions aimed at preventing infection or the development of disease following infection. There are four basic cornerstones of prophylaxis for TBD: vector prophylaxis with acaricides / repellents (directed against the ticks which carry the pathogens), chemoprophylaxis (generally targeted directly against the pathogen), vaccination (by pathogen-specific vaccination) and behavioural prophylaxis (reducing vector exposure by avoiding risk areas during the vector's periods of activity, for example; Pantchev 2013). 


\section{Acaricides / repellents}

According to the product information for certain acaricide-based products, some ticks already present at the time of treatment are not killed within the first 48 hours and remain attached and visible. It is advisable to remove such ticks mechanically before starting prophylaxis. In one study, rotating devices (in order of success: tick-pliers (tick remover/extractor), lasso, tick twister) proved better than pulling devices (tweezers, tick card). However, in regard to the tick mouthparts, there was no difference between the two groups (Robisch 2010). With the above-mentioned in mind, it is important to begin prophylaxis before the first ectoparasite exposure, e.g. efficacy against ticks develops within two days after applying a collar (using the example of imidacloprid/flumethrin in Seresto ${ }^{\circledR}$ ). Ticks infesting dogs in Europe do not tend to harm their hosts directly, with the main risk being that pathogen transmission can occur and disease potentially results from the infection. The applied compounds show different effects on ticks (repellency, antifeeding effect, disruption of attachment, expellency, killing effect), so it is important to use suitable acaricides to kill the ticks as quickly as possible before pathogens are released. It is even better to prevent ticks from attaching (tick repellency sensu stricto; Halos et al. 2012). As one study showed, compounds with a repellent effect can prevent TBD (Anaplasma/Borrelia) more efficiently than active substances, which only show a killing effect (Blagburn et al. 2005). It is therefore important for veterinarians to take note of the relevant product information.

Various acaricidal dog collars effective against ticks are licensed for use in Germany and Austria. They contain flumethrin/imidacloprid (Seresto ${ }^{\circledR}$; duration of efficacy/DOE 7 to 8 months) or deltamethrin (Scalibor ${ }^{\circledR}$; DOE 5 to 6 months) as active ingredients. Furthermore, a range of spot-on products is also available. It should be noted that products containing permethrin are to be avoided in cats because of their toxic effect on feline patients (e.g. Boland and Angles 2010). Permethrin-based products for dogs include: permethrin/imidacloprid
(Advantix ${ }^{\circledR}$; DOE for I.ricinus / R.sanguineus 4 weeks, for D. reticulatus 3 weeks), permethrin only (Exspot ${ }^{\circledR}$; DOE I. ricinus / R. sanguineus up to 4 weeks), permethrin/indoxacarb (Activyl Tick Plus $^{\circledR}$; DOE up to 5 weeks for I. ricinus, up to 3 weeks for $R$. sanguineus), permethrin/fipronil (Frontect ${ }^{\circledR}$; DOE 4 weeks), or permethrin/dinotefuran/pyriproxyfen (Vectra 3D ${ }^{\circledR}$; DOE for I. ricinus / R. sanguineus for 1 month, D.reticulatus up to 3 weeks). Non-permethrin-based products include: fipronil (Frontline ${ }^{\circledR} /$ Frontline Combo $^{\circledR}$; DOE up to 4 weeks), fipronil/amitraz/(S)-methoprene (Certifect ${ }^{\circledR}$; DOE 5 weeks), or pyriprol (Practic $^{\circledR}$; DOE 4 weeks). Collars should be adjusted to the right size, thus not too tight or too loose, with two finger-widths between the collar and the animal's neck. Spot-on products should be applied correctly, thus the spot-on solution should be applied to the skin, and not the hair of the dog, and licking off by the animal itself or companion animals needs to be prevented. Oral products using the new active substance class of isoxazolines are currently also available as fluralaner (Bravecto ${ }^{\circledR}$; DOE for I. ricinus, D. reticulatus, D. variabilis 12 weeks, for $R$. sanguineus 8 weeks), and afoxolaner (NexGard ${ }^{\circledR}$; DOE for D. reticulatus, I. ricinus, $R$. sanguineus up to 1 month) in the form of chewable tablets for dogs. These are systemic acaricides, thus ticks have to attach to the host and start to feed in order to come into contact with the active ingredients. One current study showed that afoxolaner was able to prevent infection with $B$. canis in dogs experimentally infested with D. reticulatus ticks (Beugnet et al., 2014).

\section{Vaccination}

In controlled approval studies in dogs, ectoparasiticides are usually tested using 50 adult ticks (EMEA/CVMP/005/00 Rev. 2). Consequently, $100 \%$ protection cannot be guaranteed in every case, especially in conditions of high tick exposure (numbers exceeding 50 ticks, e.g. hunting dogs). Seropositivity against $A$. phagocytophilum can also be used as an indicator of inadequate tick 
prophylaxis. Vaccination may therefore be considered in such individual cases, if available. However, it should not be regarded as a replacement for tick prophylaxis.

\section{Borrelia vaccination}

Borrelia vaccination has been a topic of controversy in recent years (Littman et al., 2006; Straubinger and Pantchev 2010; Greene et al. 2012; Pantchev 2013). One reason for this is that clinical borreliosis is rare in dogs. Koch's postulates have only been fulfilled experimentally for a clinical picture of transient fever, anorexia and clinical arthritis with lameness as well as reluctance to move, which was detected in puppies but not in dogs $\geq 6$ months (e.g. Appel et al. 1993; Straubinger 2000; Straubinger et al. 2000; Summers et al. 2005; Susta et al. 2012; Wagner et al. 2012). In contrast to humans, no erythema migrans has been observed in dogs (Appel et al. 1993), but synovial lesions were significant in infected dogs in all canine experimental studies (Appel et al. 1993; Summers et al. 2005; Susta et al. 2012; Wagner et al. 2012). After natural infection, lameness has been described in $<5 \%$ of dogs (Levy and Magnarelli 1992; McKenna et al. 1995; Hovius et al. 2000; Chou et al. 2006; Littman et al. 2006), less than 1-2\% show kidney disease (Dambach et al. 1997; Chou et al. 2006; Littman 2013), and the very rare cases with cardiac (Chou et al. 2006; Agudelo et al. 2011; Janus et al. 2014) and neurological (McKenna et al. 1995) involvement are assumed rather than documented. No association was found between exposure to either Borrelia species (or A. phagocytophilum) and neurological signs or inflammatory CNS disease in retrospective and prospective studies (Jäderlund et al. 2007, 2009), which have been subsequently confirmed by experimental infection (Krimer et al. 2011). The different clinical picture of what is seen in veterinary practice and after experimental infection in dogs is still not well understood. It has been suggested that clinical illness might result from the host's own inflammatory response (Straubinger et al. 1998; Summers et al. 2005; Greene et al.
2012). Experimental infections are performed usually only with a single breed (beagle, e.g. Summers et al. 2005), but for LN, a breed predisposition has been proposed. It might indicate that other breedrelated factors are necessary for disease development, as proposed by Appel et al. (1993) and Horney and Stojanovic (2013). Moreover, multiple exposures in nature (reinfections) or other Borrelia spp. strains (e.g. also B. miyamotoi; Schreiber et al. 2014) with a different plasmid content and virulence (Hanincova et al. 2013) are additional preconditions. For example, the risk of infection with Borrelia spp. for a single dog has been calculated to be up to $23 \%$ per year in rural areas of eastern Austria (Leschnik 2014). Experimentally, disease could be induced after repeated exposure (3 times with 2 -week intervals; tick nymphs with $16 \% \mathrm{Bbss}$ infection rate), but single exposure to 100 nymphs (same infection rate) did not result in clinical signs (Appel et al. 1993). This was supported later on by another study, where two cycles of tick challenge increased the frequency of clinical arthritis compared to a single challenge (Straubinger et al. 1998). Furthermore, co-infections transmitted by the common tick vector I. ricinus, especially A. phagocytophilum (Summers et al. 2005; Beall et al. 2008), but also other little-studied organisms in regard to their pathogenicity in the dog such as Bartonella spp. (Diniz et al. 2009), Rickettsia spp., (small) Babesia spp. (Appel et al. 1993; Skotarczak 2014) or Candidatus Neoehrlichia mikurensis (Diniz et al. 2011; Schreiber et al. 2014; see Table 1), might play a role. In particular, co-infections (by different strains or species) are probably one of the least experimentally investigated areas to date, as is the (immunological) influence of repeated infections over a longer period of time.

A further reason for controversy regarding vaccination in Europe in recent years is the fact, that different vaccines have been commercially available. For example, one vaccine contains only $B b s s$ (isolated in France from an infected I. ricinus; Wiedemann and Milward 1999) and another contains two isolates (B. garinii and B. afzelii). One 
point of controversy is that, although $B$.garinii and B. afzelii are indeed commonly found in ticks in various parts of Europe (e.g. Piesman and Gern 2004), their clinical relevance to dogs has not been conclusively demonstrated (see above). A new product available in Germany and Austria is Merilym 3 (inactivated $B b$ sl vaccine), which contains all three genospecies (Bbss, B. garinii and B. afzelii). A debatable question is whether this trivalent vaccine has advantages over purely $B b$ ss-based products. Naturally infected dogs showing clinical signs of borreliosis have been found to have co-infections with $B b$ ss and other genospecies (especially B. garinii; Hovius et al. 2000). Although the effects of co-infections in the dog have not yet been studied in an experimental model, co-infection with $B b s s$ and $B$. garinii in a murine model showed a more severe progression of symptoms than an infection with $B b$ ss alone (Hovius et al. 2007). Because it is assumed that OspA antibodies (the basis of the vaccine) are not cross-protective among Borrelia species (Straubinger et al. 2002; Töpfer 2005), it would be worth considering whether the vaccination regime should include other species ( $B$. garinii/B. afzelii) in addition to the canine pathogen $B b s s$ recognized to date. Based on its principle of action (mainly induction of antibodies to OspA; see above), vaccination prevents future infection, because anti-OspA antibodies ingested during feeding inactivate the Borrelia directly within the tick's gut (Straubinger and Pantchev 2010). Before vaccinating dogs, therefore, it is important to test adult dogs with an unknown infectious status and dogs that are already potentially infected. One reason is, that vaccination has no effect on an existing Borrelia infection. Another reason is that dogs with high ACAC following vaccination with a lyophilized product show very high levels of circulating immune complexes (Greene et al. 2012). Hebert and Eschner (2010), for example, included dogs in their vaccination programe only if they showed ACAC below $30 \mathrm{U} / \mathrm{ml}$, together with normal blood and urine values. On the other hand, dogs with ACAC over $30 \mathrm{U} / \mathrm{ml}$ were treated (doxycycline $10 \mathrm{mg} / \mathrm{kg}$ q.d. for 28 days) and followed up after 30 days (laboratory tests and clinical examination). Dogs with no abnormal findings were admitted to the vaccination programe, with the Lyme Quant C6 ELISA being repeated six months later (see above). Dogs with glomerulonephritis and suspected LN may require a longer period of doxycycline administration. In such cases (UPC above 0.5), specific recommendations regarding treatment and monitoring can be found in Goldstein et al. (2013).

\section{Babesia vaccination}

The homologous (strain-dependent) protection provided by vaccination with Pirodog ${ }^{\circledR}$ (not licensed in Germany) is around 80 to $90 \%$ in endemic regions of France but lower in other regions. This vaccine contains soluble parasite antigen (SPA) of B. canis, and a positive antibody titre ( $>1: 160)$ should develop in around $75 \%$ of animals following vaccination (source: product information). Broader protection, including protection against heterologous strains of $B$. canis, has been offered by the vaccine Nobivac Piro ${ }^{\circledR}$ (contains SPA of B. canis and B. rossi and was licensed for some years in the EU). This broader heterologous vaccine protection was achieved by the addition of B. rossi antigen (Schetters et al. 1995; Schetters 2005; Irwin 2009; Ayoob et al. 2010). However, this vaccine is not currently available on the European market.

\section{Babesia chemoprophylaxis}

The compound imidocarb, which has been used for chemoprophylaxis of infection with large Babesia, may induce potentially serious adverse effects, mainly due to cholinesterase inhibition, including also anaphylactoid reactions and renal or liver impairment (Ayoob et al. 2010; Dyachenko et al. 2012). Moreover, its prophylactic effect is of variable duration (reported to range from 2 to 6 weeks at a dose of 3-6 mg/kg BW; Deplazes et al. 2006) or even not present in sporozoite-induced experimental infections with a French B. canis isolate $(6 \mathrm{mg} /$ $\mathrm{kg}$ BW 2 to 5 weeks before infection; Uilenberg et al. 1981). In combination, it is either not recommended 
for use as chemoprophylaxis (Ayoob et al. 2010) or only for dogs under one year of age (with the recommendation that older animals should be treated if symptomatic; Tenter and Deplazes 2006). Finally, imidocarb does indeed eliminate $B$. canis, but it also prevents the development of immunity, leaving dogs susceptible to reinfection (Brandao et al. 2003).

\section{Ethical standards}

All investigations comply with the current laws of the countries in which they were performed.

\section{References}

Adaszek Ł, Banach T, Bartnicki M, Winiarczyk D, Łyp P, Winiarczyk S (2014) Application the mass spectrometry MALDI-TOF technique for detection of Babesia canis canis infection in dogs. Parasitol Res 113(11):4293-4295

Agudelo C, Schánilec P, Kybicová K, Kohout P (2011) Cardiac manifestations of borreliosis in a dog: a case report. Vet Medicina 56(2):85-92

Annen K, Friedman K, Eshoa C, Horowitz M, Gottschall J, Straus T (2012) Two cases of transfusion-transmitted Anaplasma phagocytophilum. Am J Clin Pathol 137(4):562-565

Appel MJ, Allan S, Jacobson RH, Lauderdale TL, Chang YF, Shin SJ, Thomford JW, Todhunter RJ, Summers BA (1993) Experimental Lyme disease in dogs produces arthritis and persistent infection. J Infect Dis 167(3):651-664.

Ayoob AL, Hackner SG, Prittie J (2010): Clinical management of canine babesiosis. J Vet Emerg Crit Care (San Antonio) 20(1): $77-89$

Babes V (1888) Sur l'hémoglobinurie bactérienne du boeuf. C.R. Acad. Sci., Ser. III Sci. vie 107, 692-694

Baneth G (2013) Pathophysiology and treatment of Babesiosis. Emergence of new piroplasms / diseases in dogs and cats. Proceedings of the International SCIVAC Congress "Canine Leishmaniosis and Other Vector-Borne Diseases: Our Current State of Knowledge", March $8^{\text {th }}-10^{\text {th }}$, Pisa, Italy, 28-33

Baneth G, Florin-Christensen M, Cardoso L, Schnittger L (2015) Reclassification of Theileria annae as Babesia vulpes sp. nov. Parasit Vectors 8(1):207

Barutzki D, Reule M, Scheunemann R, Heile C, Schein E (2007) Die Babesiose des Hundes. Dt Tierärztebl 55: 284-293

\section{Competing interests}

The authors declare that they have no competing interests. There is no commercial conflict of interest since the information generated here is solely for scientific dissemination.

Beck R, Vojta L, Mrljak V, Marinculić A, Beck A, Zivicnjak T, Cacciò SM (2009) Diversity of Babesia and Theileria species in symptomatic and asymptomatic dogs in Croatia. Int J Parasitol 39(7):843-848

Beall MJ, Chandrashekar R, Eberts MD, Cyr KE, Diniz PP, Mainville C, Hegarty BC, Crawford JM, Breitschwerdt EB (2008) Serological and molecular prevalence of Borrelia burgdorferi, Anaplasma phagocytophilum, and Ehrlichia species in dogs from Minnesota. Vector Borne Zoonotic Dis $8: 455-464$

Belton D (2003) Import risk analysis: Babesia gibsoni in dogs (Canis familiaris) and dog semen. Wellington: Biosecurity Authority, MAF; 19 pp

Berzina I, Krudewig C, Silaghi C, Matise I, Ranka R, Müller N, Welle M (2014) Anaplasma phagocytophilum DNA amplified from lesional skin of seropositive dogs. Ticks Tick Borne Dis 5(3):329-335

Beugnet F, Halos L, Larsen D, Labuschagné M, Erasmus H, Fourie J (2014) The ability of an oral formulation of afoxolaner to block the transmission of Babesia canis by Dermacentor reticulatus ticks to dogs. Parasit Vectors 7:283

Birkenheuer AJ, Levy MG, Breitschwerdt EB (2003): Development and evaluation of a seminested PCR for detection and differentiation of Babesia gibsoni (Asian genotype) and B. canis DNA in canine blood samples. J Clin Microbiol 41(9):4172-4177

Birkenheuer AJ (2012) Babesiosis. In: Infectious diseases of the dog and cat. $4^{\text {th }}$ edition, edited by Greene CE, Elsevier $771-784$

Blagburn BL, Spencer JA, Butler JM, Land TM, Billeter SA, Dykstra CC, Stafford, KC, Pough MB, Levy SA, Endrizzi, M, Hostetler, J (2005) Prevention of transmission of Borrelia burgdorferi and Anaplasma phagocytophilum from ticks to dogs using K9 Advantix and Frontline Plus applied 25 days before exposure to infected ticks. Intern J Appl Res Vet Med 3:69-75 
Boland LA, Angles JM (2010) Feline permethrin toxicity: retrospective study of 42 cases. J Feline Med Surg 12(2):61-71

Boozer L, Macintire D (2005) Babesia gibsoni: An Emerging Pathogen in Dogs. Compendium 27(1): 33-41

Brandão LP, Hagiwara MK, Myiashiro SI (2003) Humoral immunity and reinfection resistance in dogs experimentally inoculated with Babesia canis and either treated or untreated with imidocarb dipropionate. Vet Parasitol 114(4):253-265

Brianti E, Otranto D, Dantas-Torres F, Weigl S, Latrofa MS, Gaglio G, Napoli E, Brucato G, Cauquil L, Giannetto S, Bain O (2012) Rhipicephalus sanguineus (Ixodida, Ixodidae) as intermediate host of a canine neglected filarial species with dermal microfilariae. Vet Parasitol 183(3-4):330-337

Brisson D, Drecktrah D, Eggers CH, Samuels DS (2012) Genetics of Borrelia burgdorferi. Annu Rev Genet 46:515-536

Bykowski T, Babb K, von Lackum K, Riley SP, Norris SJ, Stevenson B (2006) Transcriptional regulation of the Borrelia burgdorferi antigenically variable VlsE surface protein. J Bacteriol 188(13):4879-4889

Carrade DD, Foley JE, Borjesson DL, Sykes JE (2009) Canine granulocytic anaplasmosis: a review. J Vet Intern Med 23(6):1129-1141

Carret C, Walas F, Carcy B, Grande N, Précigout E, Moubri K, Schetters TP, Gorenflot A (1999) Babesia canis canis, Babesia canis vogeli, Babesia canis rossi: differentiation of the three subspecies by a restriction fragment length polymorphism analysis on amplified small subunit ribosomal RNA genes. J Eukaryot Microbiol 46(3):298-303

Center SA, Wilkinson E, Smith CA, Erb H, Lewis RM (1985) 24-Hour urine protein/creatinine ratio in dogs with proteinlosing nephropathies. J Am Vet Med Assoc 187(8):820-824

Chandrashekar R, Mainville CA, Beall MJ, O'Connor T, Eberts MD, Alleman AR, Gaunt SD, Breitschwerdt EB (2010) Performance of a commercially available in-clinic ELISA for the detection of antibodies against Anaplasma phagocytophilum, Ehrlichia canis, and Borrelia burgdorferi and Dirofilaria immitis antigen in dogs. Am J Vet Res 71(12):1443-1450

Chang YF, Straubinger RK, Jacobson RH, Kim JB, Kim TJ, Kim D, Shin SJ, Appel MJG (1996) Dissemination of Borrelia burgdorferi after experimental infection in dogs. J Spirochetal Tick-Borne Dis 3:80-86

Chauvin A, Moreau E, Bonnet S, Plantard O, Malandrin L (2009) Babesia and its hosts: adaptation to long-lasting interactions as a way to achieve efficient transmission. Vet Res 40(2):37
Chou J, Wünschmann A, Hodzic E, Borjesson DL (2006) Detection of Borrelia burgdorferi DNA in tissues from dogs with presumptive Lyme borreliosis. J Am Vet Med Assoc 229(8):1260-1265

Crippa M, Rais O, Gern L (2002) Investigations on the mode and dynamics of transmission and infectivity of Borrelia burgdorferi sensu strictu and Borrelia afzelii in Ixodes ricinus ticks. Vector Borne Zoonotic Dis 2: 3-9

Dambach DM, Smith CA, Lewis RM, Van Winkle TJ (1997) Morphologic, immunohistochemical, and ultrastructural characterization of a distinctive renal lesion in dogs putatively associated with Borrelia burgdorferi infection: 49 cases (1987-1992). Vet Pathol 34(2):85-96

Dantas-Torres F, Otranto D (2014a) Further thoughts on the taxonomy and vector role of Rhipicephalus sanguineus group ticks. Vet Parasitol pii: S0304-4017(14)00648-7. doi: 10.1016/j.vetpar.2014.12.014

Dantas-Torres F, Otranto D (2014b) When is an "asymptomatic" dog asymptomatic? Vet Parasitol 202(3-4):341-342

de la Fuente J, Estrada-Pena A, Venzal JM, Kocan KM, Sonenshine DE (2008) Overview: Ticks as vectors of pathogens that cause disease in humans and animals. Front Biosci $13: 6938-6946$

Demeter Z, Palade EA, Balogh E, Jakab C, Farkas R, Tánczos B, Hornok S (2011) Postmortem small babesia-like morphology of Babesia canis - short communication. Acta Vet Hung 59(4):427-432

Deplazes P, Staebler S, Gottstein B (2006) [Travel medicine of parasitic diseases in the dog]. Reisemedizin parasitärer Erkrankungen des Hundes. Schweiz Arch Tierheilk 148: 447-461, in German

Deplazes P, Eckert J, von Samson-Himmelstjerna G, Zahner H (2013) [Textbook of Parasitology for the Veterinary Medicine]. Lehrbuch der Parasitologie für die Tiermedizin, Enke Verlag, $3^{\text {th }}$ edition, $639 \mathrm{pp}$, in German

Dhand A, Nadelman RB, Aguero-Rosenfeld M, Haddad FA, Stokes DP, Horowitz HW (2007) Human granulocytic anaplasmosis during pregnancy: case series and literature review. Clin Infect Dis 45(5):589-593

Diniz PP, Wood M, Maggi RG, Sontakke S, Stepnik M, Breitschwerdt EB (2009) Co-isolation of Bartonella henselae and Bartonella vinsonii subsp. berkhoffii from blood, joint and subcutaneous seroma fluids from two naturally infected dogs. Vet Microbiol 138(3-4):368-372

Diniz PP, Schulz BS, Hartmann K, Breitschwerdt EB (2011) "Candidatus Neoehrlichia mikurensis" infection in a dog from Germany. J Clin Microbiol 49(5):2059-2062 
Diniz PP, Breitschwerdt EB (2012) Anaplasma phagocytophilum infection (canine granulocytotropic anaplasmosis). In: Infectious diseases of the dog and cat. $4^{\text {th }}$ edition, edited by Greene CE, Elsevier 244-254

Dixit P, Dixit AK, Varshney JP (2010) Evidence of new pathogenic Theileria species in dogs. J Parasit Dis 34(1):29-32

Dongus H, Zahler M, Gothe R (1996) [The brown dog tick, Rhipicephalus sanguineus (Ixodidae), in Germany: an epidemiologic study and control measures]. Berl Münch Tierarztl Wochenschr 109(6-7):245-248, in German

Dumler JS, Barbet AF, Bekker CP, Dasch GA, Palmer GH, Ray SC, Rikihisa Y, Rurangirwa FR (2001) Reorganization of genera in the families Rickettsiaceae and Anaplasmataceae in the order Rickettsiales: unification of some species of Ehrlichia with Anaplasma, Cowdria with Ehrlichia and Ehrlichia with Neorickettsia, descriptions of six new species combinations and designation of Ehrlichia equi and 'HGE agent' as subjective synonyms of Ehrlichia phagocytophila. Int J Syst Evol Microbiol 51(6):2145-2165

Duscher G, Fuehrer HP, Kübber-Heiss A (2014) Fox on the run - molecular surveillance of fox blood and tissue for the occurrence of tick-borne pathogens in Austria. Parasit Vectors $7(1): 521$

Dyachenko V, Pantchev N, Balzer HJ, Meyersen A, Straubinger RK (2012) First case of Anaplasma platys infection in a dog from Croatia. Parasit Vectors 5:49

Egenvall AE, Hedhammar AA, Bjöersdorff AI (1997) Clinical features and serology of 14 dogs affected by granulocytic ehrlichiosis in Sweden. Vet Rec 140(9):222-226

Eichenberger RM, Deplazes P, Mathis A (2015): Ticks on dogs and cats: A pet owner-based survey in a rural town in northeastern Switzerland. Ticks Tick Borne Dis pii: S1877-959X(15)00023-0. doi: 10.1016/j.ttbdis.2015.01.007 [Epub ahead of print]

Eiras DF, Craviotto MB, Baneth G, Moré G (2014) First report of Rangelia vitalii infection (canine rangeliosis) in Argentina. Parasitol Int 63(5):729-734

Embers ME, Jacobs MB, Johnson BJ, Philipp MT (2007) Dominant epitopes of the C6 diagnostic peptide of Borrelia burgdorferi are largely inaccessible to antibody on the parent VlsE molecule. Clin Vaccine Immunol 14(8):931-936

Embers ME, Barthold SW, Borda JT, Bowers L, Doyle L, Hodzic E, Jacobs MB, Hasenkampf NR, Martin DS, Narasimhan S, Phillippi-Falkenstein KM, Purcell JE, Ratterree MS, Philipp MT (2012) Persistence of Borrelia burgdorferi in rhesus macaques following antibiotic treatment of disseminated infection. PLoS One 7(1):e29914
Falkenö U, Tasker S, Osterman-Lind E, Tvedten HW (2013) Theileria annae in a young Swedish dog. Acta Vet Scand $55: 50$

Farkas R, Takács N, Hornyák Á, Nachum-Biala Y, Hornok S, Baneth G (2015) First report on Babesia cf. microti infection of red foxes (Vulpes vulpes) from Hungary. Parasit Vectors 8(1):55

Gallusová M, Qablan MA, D’Amico G, Oborník M, Petrželková KJ, Mihalca AD, Modrý D (2014) Piroplasms in feral and domestic equines in rural areas of the Danube Delta, Romania, with survey of dogs as a possible reservoir. Vet Parasitol 206(3-4):287-292

Gaunt S, Beall M, Stillman B, Lorentzen L, Diniz P, Chandrashekar R, Breitschwerdt E (2010) Experimental infection and co-infection of dogs with Anaplasma platys and Ehrlichia canis: hematologic, serologic and molecular findings. Parasit Vectors 3(1):33

Gauthier DT, Mansfield LS (1999) Western immunoblot analysis for distinguishing vaccination and infection status with Borrelia burgdorferi (Lyme disease) in dogs. J Vet Diagn Invest 11(3):259-265

Globokar Vrhovec M (2013) Retrospektive Analyse der parasitologischen Untersuchungs-ergebnisse eines privaten Untersuchungslabors: Intestinale, respiratorische und vektorübertragene Parasitosen bei Hunden und Katzen in Deutschland (2004-2006). Inaugural-Dissertation, JustusLiebig-Universität Giessen, 276 pp, in German

Goldstein RE, Atwater DZ (2006) Evaluation of serology and circulating immune complexes in dogs naturally infected with Borrelia burgdorferi. Proceedings of the $24^{\text {th }}$ ACVIM Forum 2006; [abstract \#12]; 732

Goldstein RE, Cordner AP, Sandler JL, Bellohusen BA, Erb HN (2007) Microalbuminuria and comparison of serologic testing for exposure to Borrelia burgdorferi in nonclinical Labrador and Golden Retrievers. J Vet Diagn Invest 19(3):294-297

Goldstein RE, Brovida C, Fernández-Del Palacio MJ, Littman MP, Polzin DJ, Zatelli A, Cowgill LD (2013) Consensus recommendations for treatment for dogs with serology positive glomerular disease. IRIS Glomerular Disease Study Group, J Vet Intern Med 27: Suppl 1:S60-66

Greene CE, Straubinger RK, Levy SA (2012) Borreliosis. In: Infectious diseases of the dog and cat. $4^{\text {th }}$ edition, edited by Greene CE, Elsevier 447-465

Greig B, Asanovich KM, Armstrong PJ, Dumler JS (1996) Geographic, clinical, serologic, and molecular evidence of granulocytic ehrlichiosis, a likely zoonotic disease, in Minnesota and Wisconsin dogs. J Clin Microbiol 34(1):44-48 
Halos L, Baneth G, Beugnet F, Bowman AS, Chomel B, Farkas R, Franc M, Guillot J, Inokuma H, Kaufman R, Jongejan F, Joachim A, Otranto D, Pfister K, Pollmeier M, Sainz A, Wall R (2012) Defining the concept of "tick repellency" in veterinary medicine. Parasitology 139(4):419-423

Hanincova K, Mukherjee P, Ogden NH, Margos G, Wormser GP, Reed KD, Meece JK, Vandermause MF, Schwartz I (2013) Multilocus sequence typing of Borrelia burgdorferi suggests existence of lineages with differential pathogenic properties in humans. PLoS One 8(9):e73066

Harrus S, Waner T (2011) Diagnosis of canine monocytotropic ehrlichiosis (Ehrlichia canis): an overview. Vet J 187(3):292-296

Harrus S, Waner T, Neer TM (2012) Ehrlichia canis infection. In: Infectious diseases of the dog and cat. $4^{\text {th }}$ edition, edited by Greene CE, Elsevier 227-238

Hebert D, Eschner A (2010) Seroprevalence of Borrelia burgdorferi-specific $\mathrm{C} 6$ antibody in dogs before and after implementation of a nonadjuvanted recombinant outer surface protein A vaccine in a Rhode Island small animal clinic. Vet Ther 11(3):E1-9

Heile C, Heydorn AO, Schein E (2006) [Dermacentor reticulatus (Fabricius, 1794)-distribution, biology and vector for Babesia canis in Germany]. Dermacentor reticulatus (Fabricius, 1794) - Verbreitung, Biologie und Vektor von Babesia canis in Deutschland. Berl Münch Tierarztl Wochenschr 119(7-8):330-34, in German

Heile C, Schein E (2007) Kürzeste Übertragungszeiten von Babesia canis canis durch Dermacentor reticulatus. VetMedReport, Sonderausgabe V5, Volume 31, Berlin, May, p. 2

Henniger T, Henniger P, Grossmann T, Distl O, Ganter M, von Loewenich FD (2013) Congenital infection with Anaplasma phagocytophilum in a calf in northern Germany. Acta Vet Scand 55:3

Herzberger P, Siegel C, Skerka C, Fingerle V, Schulte-Spechtel U, van Dam A, Wilske B, Brade V, Zipfel PF, Wallich R, Kraiczy P (2007) Human pathogenic Borrelia spielmanii sp. nov. resists complement-mediated killing by direct binding of immune regulators factor $\mathrm{H}$ and factor $\mathrm{H}$-like protein 1 . Infect Immun 75(10):4817-4825

Hirsch M, Pantchev N (2008) [Occurrence of travel diseases leishmaniasis, ehrlichiosis, babesiosis, and dirofilariosis in dogs living in Germany]. Vorkommenshäufigkeit der Reisekrankheiten Leishmaniose, Ehrlichiose, Babesiose und Dirofilariose bei in Deutschland lebenden Hunden. Kleintierpraxis 53:154-165, in German

Horney BS, Stojanovic V (2013) Protein-losing nephropathy associated with Borrelia burgdorferi seropositivity in a soft-coated wheaten terrier: response to therapy. Can Vet J 54(4):392-396
Horowitz HW, Kilchevsky E, Haber S, Aguero-Rosenfeld M, Kranwinkel R, James EK, Wong SJ, Chu F, Liveris D, Schwartz I (1998) Perinatal transmission of the agent of human granulocytic ehrlichiosis. N Engl J Med 339(6):375-378

Horst H (Ed.) (2003) [Tick borreliosis Lyme disease in humans and animals]. Zeckenborreliose Lyme-Krankheit bei Mensch und Tier. Spitta Verlag, $4^{\text {th }}$ edition; $224 \mathrm{pp}$, in German

Hovius JW, Hovius KE, Oei A, Houwers DJ, van Dam AP (2000) Antibodies against specific proteins of and immobilizing activity against three strains of Borrelia burgdorferi sensu lato can be found in symptomatic but not in infected asymptomatic dogs. J Clin Microbiol 38(7):2611-2621

Hovius JW, Li X, Ramamoorthi N, van Dam AP, Barthold SW, van der Poll T, Speelman P, Fikrig E (2007) Coinfection with Borrelia burgdorferi sensu stricto and Borrelia garinii alters the course of murine Lyme borreliosis. FEMS Immunol Med Microbiol 49(2):224-234

Hovius KE (2013): Canine borreliosis. In: Guide to vector borne diseases of pets. $1^{\text {th }}$ edition, edited by Beugnet $F$, Merial 218-230

Huhn C, Winter C, Wolfsperger T, Wüppenhorst N, Strašek Smrdel K, Skuballa J, Pfäffle M, Petney T, Silaghi C, Dyachenko V, Pantchev N, Straubinger RK, SchaarschmidtKiener D, Ganter M, Aardema ML, von Loewenich FD (2014) Analysis of the population structure of Anaplasma phagocytophilum using multilocus sequence typing. PLoS One 9(4):e93725

Ionita M, Mitrea IL, Pfister K, Hamel D, Silaghi C (2013) Molecular evidence for bacterial and protozoan pathogens in hard ticks from Romania. Vet Parasitol 196(1-2):71-76

Irwin PJ (2009) Canine babesiosis: from molecular taxonomy to control. Parasit Vectors 2 Suppl 1:S4

Jäderlund KH, Egenvall A, Bergström K, Hedhammar A (2007) Seroprevalence of Borrelia burgdorferi sensu lato and Anaplasma phagocytophilum in dogs with neurological signs. Vet Rec 160(24):825-831

Jäderlund KH, Bergström K, Egenvall A, Hedhammar A (2009) Cerebrospinal fluid PCR and antibody concentrations against Anaplasma phagocytophilum and Borrelia burgdorferi sensu lato in dogs with neurological signs. J Vet Intern Med 23(3):669-672

Janus I, Noszczyk-Nowak A, Nowak M, Cepiel A, Ciaputa R, Pasławska U, Dzięgiel P, Jabłońska K (2014) Myocarditis in dogs: etiology, clinical and histopathological features (11 cases: 2007-2013). Ir Vet J 67(1):28 
Jongejan F, Fourie JJ, Chester ST, Manavella C, Mallouk Y, Pollmeier MG, Baggott D (2011) The prevention of transmission of Babesia canis canis by Dermacentor reticulatus ticks to dogs using a novel combination of fipronil, amitraz and (S)-methoprene. Vet Parasitol 179(4):343-350

Kahl O, Janetzki-Mittmann C, Gray JS, Jonas R, Stein J, de Boer R (1998) Risk of infection with Borrelia burgdorferi sensu lato for a host in relation to the duration of nymphal Ixodes ricinus feeding and the method of tick removal. Zentralbl Bakteriol 287(1-2):41-52

Kenedy MR, Lenhart TR, Akins DR (2012) The role of Borrelia burgdorferi outer surface proteins. FEMS Immunol Med Microbiol 66(1):1-19

Kjelgaard-Hansen M, Jensen AL, Houser GA, Jessen LR, Kristensen AT (2006) Use of serum C-reactive protein as an early marker of inflammatory activity in canine type II immune-mediated polyarthritis: case report. Acta Vet Scand $48: 9$

Kohn B, Galke D, Beelitz P, Pfister K (2008) Clinical features of canine granulocytic anaplasmosis in 18 naturally infected dogs. J Vet Intern Med 22(6):1289-1295

Krämer F, Schaper R, Schunack B, Połozowski A, Piekarska J, Szwedko A, Jodies R, Kowalska D, Schüpbach D, Pantchev N (2014) Serological detection of Anaplasma phagocytophilum, Borrelia burgdorferi sensu lato and Ehrlichia canis antibodies and Dirofilaria immitis antigen in a countrywide survey in dogs in Poland. Parasitol Res 113(9):3229-3239

Krimer PM, Miller AD, Li Q, Grosenbaugh DA, Susta L, Schatzberg SJ (2011) Molecular and pathological investigations of the central nervous system in Borrelia burgdorferiinfected dogs. J Vet Diagn Invest 23(4):757-763

Krücken J, Schreiber C, Maaz D, Kohn M, Demeler J, Beck S, Schein E, Olias P, Richter D, Matuschka FR, Pachnicke S, Krieger K, Kohn B, von Samson-Himmelstjerna G (2013) A novel high-resolution melt PCR assay discriminates Anaplasma phagocytophilum and "Candidatus Neoehrlichia mikurensis”. J Clin Microbiol 51(6):1958-1961

Krupka I, Pantchev N, Weise M, Straubinger RK (2007) [Tick-transmitted, bacterial infections in dogs: Seroprevalences of Anaplasma phagocytophilum, Borrelia burgdorferi sensu lato and Ehrlichia canis in Germany]. Durch Zecken übertragbare bakterielle Infektionen bei Hunden: Seroprävalenzen von Anaplasma phagocytophilum, Borrelia burgdorferi sensu lato und Ehrlichia canis in Deutschland. Praktischer Tierarzt 10(88):776-787, in German

Krupka I, Straubinger RK (2010) Lyme borreliosis in dogs and cats: background, diagnosis, treatment and prevention of infections with Borrelia burgdorferi sensu stricto. Vet Clin North Am Small Anim Pract 40(6):1103-1119
Kurzová Z, Kodym P, Balátová $\mathrm{P}$, Berenová D, Hořejší J, Pícha D (2014) Are serological tests capable of discriminating between different borrelia species? Proceedings of the V4 Parasitological Meeting "Parasites in the Heart of Europe", May $25^{\text {th }}-30^{\text {th }}$, Stará Lesná, Slovakia, 93-94

Leschnik MW, Kirtz G, Khanakah G, Duscher G, Leidinger E, Thalhammer JG, Joachim A, Stanek G (2010) Humoral immune response in dogs naturally infected with Borrelia burgdorferi sensu lato and in dogs after immunization with a Borrelia vaccine. Clin Vaccine Immunol 17(5):828-835

Leschnik M (2014) Canine borreliosis: are we facing the facts? Vet J 199(2):197-198

Levy SA, Magnarelli LA (1992) Relationship between development of antibodies to Borrelia burgdorferi in dogs and the subsequent development of limb/joint borreliosis. J Am Vet Med Assoc 200(3):344-347

Levy SA, O'Connor TP, Hanscom JL, Shields P, Lorentzen L, Dimarco AA (2008) Quantitative measurement of C6 antibody following antibiotic treatment of Borrelia burgdorferi antibody-positive nonclinical dogs. Clin Vaccine Immunol 15(1):115-119

Liang FT, Steere AC, Marques AR, Johnson BJ, Miller JN, Philipp MT (1999a) Sensitive and specific serodiagnosis of Lyme disease by enzyme-linked immunosorbent assay with a peptide based on an immunodominant conserved region of Borrelia burgdorferi VlsE. J Clin Microbiol 37(12):3990-3996

Liang FT, Alvarez AL, Gu Y, Nowling JM, Ramamoorthy R, Philipp MT (1999b) An immunodominant conserved region within the variable domain of $\mathrm{VlsE}$, the variable surface antigen of Borrelia burgdorferi. J Immunol 163(10):5566-5573

Liang FT, Aberer E, Cinco M, Gern L, Hu CM, Lobet YN, Ruscio M, Voet PE Jr, Weynants VE, Philipp MT (2000a) Antigenic conservation of an immunodominant invariable region of the VlsE lipoprotein among European pathogenic genospecies of Borrelia burgdorferi SL. J Infect Dis 182(5):1455-1462

Liang FT, Jacobson RH, Straubinger RK, Grooters A, Philipp MT (2000b) Characterization of a Borrelia burgdorferi VlsE invariable region useful in canine Lyme disease serodiagnosis by enzyme-linked immunosorbent assay. J Clin Microbiol 38(11):4160-4166

Liebisch A, Liebisch G (2003a) [Tick borreliosis in domestic animals]. Zeckenborreliose bei Haustieren. In [Tick borreliosis Lyme disease in humans and animals]. Zeckenborreliose Lyme-Krankheit bei Mensch und Tier. $4^{\text {th }}$ edition. Edited by Horst H. Spitta Verlag; 194-241, in German 
Liebisch A, Liebisch G (2003b) [Biology and ecology of ticks]. Biologie und Ökologie der Zecken. In: [Tick borreliosis Lyme disease in humans and animals]. Zeckenborreliose Lyme-Krankheit bei Mensch und Tier. $4^{\text {th }}$ edition, edited by Horst H, Spitta Verlag 32-49, in German

Lin T, Gao L, Edmondson DG, Jacobs MB, Philipp MT, Norris SJ (2009) Central role of the Holliday junction helicase RuvAB in VlsE recombination and infectivity of Borrelia burgdorferi. PLoS Pathog 5(12):e1000679

Littman MP, Goldstein RE, Labato MA, Lappin MR, Moore GE (2006) ACVIM small animal consensus statement on Lyme disease in dogs: diagnosis, treatment, and prevention. J Vet Intern Med 20:422-434

Littman MP (2013) Lyme nephritis. J Vet Emerg Crit Care (San Antonio) 23(2):163-173

Margos G, Wilske B, Sing A, Hizo-Teufel C, Cao WC, Chu C, Scholz H, Straubinger RK, Fingerle V (2013) Borrelia bavariensis sp. nov. is widely distributed in Europe and Asia. Int J Syst Evol Microbiol 63(11):4284-4288

McKenna P, Clement J, Van Dijck D, Lauwerys M, Carey D, Van den Bogaard T, Bigaignon G (1995) Canine Lyme disease in Belgium. Vet Rec 136(10):244-247

Mierzejewska EJ, Welc-Falęciak R, Bednarska M, Rodo A, Bajer A (2014) The first evidence for vertical transmission of Babesia canis in a litter of Central Asian Shepherd dogs. Ann Agric Environ Med 21(3):500-503

Minkus G, Breuer W, Wanke R, Reusch C, Leuterer G, Brem G, Hermanns W (1994) Familial nephropathy in Bernese mountain dogs. Vet Pathol 31(4):421-428

Moehrle M, Rassner G (2002) How to remove ticks? Dermatology 204(4):303-304

Najm NA, Meyer-Kayser E, Hoffmann L, Herb I, Fensterer V, Pfister K, Silaghi C (2014) A molecular survey of Babesia spp. and Theileria spp. in red foxes (Vulpes vulpes) and their ticks from Thuringia, Germany. Ticks Tick Borne Dis 5(4):386-391

O’Connor TP, Esty KJ, Hanscom JL, Shields P, Philipp MT (2004) Dogs vaccinated with common Lyme disease vaccines do not respond to IR6, the conserved immunodominant region of the VlsE surface protein of Borrelia burgdorferi. Clin Diagn Lab Immunol 11(3):458-462

Ogo NI, Lawal AI, Okubanjo OO, Kamani J, Ajayi OO (2011) Current status of canine babesiosis and the situation in Nigeria: a review. Nigerian Veterinary Journal Vol 32(2):69-78

Olmeda-García AS, Rodríguez-Rodríguez JA, Rojo-Vázquez FA (1993) Experimental transmission of Dipetalonema dracunculoides (Cobbold 1870) by Rhipicephalus sanguineus (Latreille 1806). Vet Parasitol 47(3-4):339-342
Pantchev N, Schaper R, Limousin S, Norden N, Weise M, Lorentzen L (2009) Occurrence of Dirofilaria immitis and tick-borne infections caused by Anaplasma phagocytophilum, Borrelia burgdorferi sensu lato and Ehrlichia canis in domestic dogs in France: results of a countrywide serologic survey. Parasitol Res 105(Suppl):S101-S113

Pantchev N (2010a) C-reactive protein as a marker in canine granulocytic anaplasmosis. Vet Rec 166(20):632

Pantchev N (2010b) Canine granulozytäre Anaplasmose beim Hund - Teil 2: Diagnostik, Therapie und Prophylaxe. tierärztliches journal reise \& medizin 6: 32-33

Pantchev N (2012a): Zeckenübertragene Reiseinfektionen beim Hund: Ehrlichiose und Babesiose. veterinärSPIEGEL 4: $162-170$

Pantchev N (2012b) Aktuelle Situation und Bedeutung der vektorübertragenen Erkrankungen Borreliose, Anaplasmose und Leishmaniose beim Hund. Kompendium Kleintier 2012: $4-10$

Pantchev N (2013) Halsband, Spot-on, Tablette und Co. Wie schützt man den Hund gegen CVBD? Kompendium Kleintier 2013: 14-22

Pantchev N (2014) Understanding the complexity of diagnosis and monitoring of canine Lyme disease. Proceedings of Merial pre-congress symposium, $24^{\text {th }}$ annual congress ECVIM-CA, 03.09.2014, Mainz, 13-19

Petney TN, Pfäffle MP, Skuballa JD (2012) An annotated checklist of the ticks (Acari: Ixodida) of Germany. Systematic and Applied Acarology 17(2):115-170

Piana GP, Galli-Valerio B (1895): Su di un infezione del cane con parasiti endoglobulari. Il Moderno Zooiatro 6, 163-169

Piesman J, Gern L (2004) Lyme borreliosis in Europe and North America. Parasitology 129 Suppl:S191-220

Radolf JD, Caimano MJ (2008) The long strange trip of Borrelia burgdorferi outer-surface protein C. Mol Microbiol $69(1): 1-4$

Rizzoli A, Silaghi C, Obiegala A, Rudolf I, Hubalek Z, Foldvari G, Plantard O, Vayssier-Taussat M, Bonnet S, Spitalska E, Kazimirova M (2014) Ixodes ricinus and its transmitted pathogens in urban and peri-urban areas in Europe: new hazards and relevance for public health. Front Public Health 2:251

Robisch K (2010) [Tick removal - Comparison of five different tick removal devices]. Tick Removal - Vergleich von fünf verschiedenen Zeckenentfernungsgeräten. Diplomarbeit zur Erlangung der Würde eines Diplomtierarztes der Veterinärmedizinischen Universität Wien, 67 pp, in German 
Rolla D, Conti N, Ansaldo F, Panaro L, Lusenti T (2013) Post-infectious glomerulonephritis presenting as acute renal failure in a patient with Lyme disease. J Renal Inj Prev (1): $17-20$

Rollend L, Fish D, Childs JE (2013) Transovarial transmission of Borrelia spirochetes by Ixodes scapularis: a summary of the literature and recent observations. Ticks Tick Borne Dis 4(1-2):46-51

Rosa CT, Pazzi P, Nagel S, McClure V, Christie J, Troskie M, Dvir E (2014) Theileriosis in six dogs in South Africa and its potential clinical significance. J S Afr Vet Assoc 85(1):1-7

Schaarschmidt D, Gilli U, Gottstein B, Marreros N, Kuhnert P, Daeppen JA, Rosenberg G, Hirt D, Frey CF (2013) Questing Dermacentor reticulatus harbouring Babesia canis DNA associated with outbreaks of canine babesiosis in the Swiss Midlands. Ticks Tick Borne Dis 4(4):334-340

Schetters TH, Kleuskens J, Scholtes N, Bos HJ (1995) Strain variation limits protective activity of vaccines based on soluble Babesia canis antigens. Parasite Immunol 17(4):215-218

Schetters T (2005) Vaccination against canine babesiosis. Trends Parasitol 21(4):179-184

Schreiber C, Krücken J, Beck S, Maaz D, Pachnicke S, Krieger K, Gross M, Kohn B, von Samson-Himmelstjerna G (2014) Pathogens in ticks collected from dogs in Berlin/ Brandenburg, Germany. Parasit Vectors 7(1):535

Scorpio DG, Dumler JS, Barat NC, Cook JA, Barat CE, Stillman BA, DeBisceglie KC, Beall MJ, Chandrashekar R (2011) Comparative strain analysis of Anaplasma phagocytophilum infection and clinical outcomes in a canine model of granulocytic anaplasmosis. Vector Borne Zoonotic Dis 11(3):223-229

Simões PB, Cardoso L, Araújo M, Yisaschar-Mekuzas Y, Baneth G (2011) Babesiosis due to the canine Babesia microtilike small piroplasm in dogs - first report from Portugal and possible vertical transmission. Parasit Vectors 4:50

Skotarczak B (2014) Why are there several species of Borrelia burgdorferi sensu lato detected in dogs and humans? Infect Genet Evol 23:182-188

Štefančíková A, Derdáková M, Škardová I, Szestáková E, Čisláková L, Kováčová D, Stanko M, Petko B (2008) Some epidemiological and epizootiological aspects of Lyme borreliosis in Slovakia with the emphasis on the problems of serological diagnostics. Biologia 63(6):1135-1142

Straubinger RK, Straubinger AF, Summers BA, Jacobson RH, Erb HN (1998) Clinical manifestations, pathogenesis, and effect of antibiotic treatment on Lyme borreliosis in dogs. Wien Klin Wochenschr 110(24):874-881
Straubinger RK (2000) PCR-based quantification of Borrelia burgdorferi organisms in canine tissues over a 500-day postinfection period. J Clin Microbiol 38(6):2191-2199

Straubinger RK, Straubinger AF, Summers BA, Jacobson RH (2000) Status of Borrelia burgdorferi infection after antibiotic treatment and the effects of corticosteroids: an experimental study. J Infect Dis 181(3):1069-1081

Straubinger RK, Dharma Rao T, Davidson E, Summers BA, Jacobson RH, Frey AB (2002) Protection against tick-transmitted Lyme disease in dogs vaccinated with a multiantigenic vaccine. Vaccine 20(1-2):181-193

Straubinger RK, Pantchev N (2010) Die Lyme-BorrelioseImpfung beim Hund - kontrovers diskutiert. kleintier.konkret 5: 8-11

Summers BA, Straubinger AF, Jacobson RH, Chang YF, Appel MJ, Straubinger RK (2005) Histopathological studies of experimental Lyme disease in the dog. J Comp Pathol 133(1):1-13

Susta L, Uhl EW, Grosenbaugh DA, Krimer PM (2012) Synovial lesions in experimental canine Lyme borreliosis. Vet Pathol 49(3):453-461

Tappe J, Jordan D, Janecek E, Fingerle V, Strube C (2014) Revisited: Borrelia burgdorferi sensu lato infections in hard ticks (Ixodes ricinus) in the city of Hanover (Germany). Parasit Vectors 7:441

Tenter AM, Deplazes P (2006) [Protozoal infections in dog and cat]. Protozoeninfektionen von Hund und Katze. In: [Parasitology for the Veterinary Medicine]. Veterinärmedizinische Parasitologie. $6^{\text {th }}$ edition, edited by Schnieder T, Parey 409-444

Tijsse-Klasen E, Hansford KM, Jahfari S, Phipps P, Sprong H, Medlock JM (2013a) Spotted fever group rickettsiae in Dermacentor reticulatus and Haemaphysalis punctata ticks in the UK. Parasit Vectors 6:212

Tijsse-Klasen E, Pandak N, Hengeveld P, Takumi K, Koopmans MP, Sprong H (2013b) Ability to cause erythema migrans differs between Borrelia burgdorferi sensu lato isolates. Parasit Vectors 6:23

Tilly K, Bestor A, Rosa PA (2013) Lipoprotein succession in Borrelia burgdorferi: similar but distinct roles for OspC and $\mathrm{VlsE}$ at different stages of mammalian infection. Mol Microbiol 89(2):216-227 
Töpfer K (2005) [Characterization of the humoral immune response in dogs after vaccination against the causative agent of the Lyme Borreliosis, Borrelia burgdorferi, with different vaccines using two different vaccination schedules]. Charakterisierung der humoralen Immunantwort im Hund nach Impfung mit verschiedenen Impfstoffen gegen den Erreger der Lyme-Borreliose, Borrelia burgdorferi, unter Berücksichtigung zweier verschiedener Impfstrategien. Inaugural-Dissertation zur Erlangung des Grades eines Doctor medicinae veterinariae (Dr. med. vet.) durch die Veterinärmedizinische Fakultät der Universität Leipzig, 115 pp, in German

Tsao JI (2009) Reviewing molecular adaptations of Lyme borreliosis spirochetes in the context of reproductive fitness in natural transmission cycles. Vet Res 40(2):36

Uilenberg G, Verdiesen PA, Zwart D (1981) Imidocarb: a chemoprophylactic experiment with Babesia canis. Vet Q. 3(3): $118-123$

Uilenberg G, Franssen FF, Perié NM, Spanjer AA (1989) Three groups of Babesia canis distinguished and a proposal for nomenclature. Vet Q 11(1):33-40

Wagner B, Freer H, Rollins A, Garcia-Tapia D, Erb HN, Earnhart C, Marconi R, Meeus P (2012) Antibodies to Borrelia burgdorferi OspA, OspC, OspF, and C6 antigens as markers for early and late infection in dogs. Clin Vaccine Immunol 19(4):527-535

Wang J, Dyachenko V, Munderloh UG, Straubinger RK (2015) Transmission of Anaplasma phagocytophilum from endothelial cells to peripheral granulocytes in vitro under shear flow conditions. Med Microbiol Immunol [Epub ahead of print]
Wiedemann C, Milward F (1999) [Efficacy and safety studies with a new vaccine against Lyme Borreliosis in dogs (Meri$\left.\operatorname{lym}^{\circledR}\right)$ ]. Wirksamkeits- und Vertäglichkeitsprüfungen mit einem neuen Impfstoff gegen Lyme-Borreliose beim Hund. TÄ Umschau 54(5):242-249

Wilking H, Fingerle V, Klier C, Thamm M, Stark K (2015) Antibodies against Borrelia burgdorferi sensu lato among adults, Germany, 2008-2011. Emerg Infect Dis 21(1): $107-110$

Woldehiwet Z (2010) The natural history of Anaplasma phagocytophilum. Vet Parasitol 167(2-4):108-122

Wolf D, Failing K, Taubert A, Pantchev N (2014) Serological diagnosis of canine leishmaniosis: comparison of three commercially available tests. Parasitol Res 113(5):1997-2002

Zahler M, Schein E, Rinder H, Gothe R (1998) Characteristic genotypes discriminate between Babesia canis isolates of differing vector specificity and pathogenicity to dogs. Parasitol Res 84(7):544-548.

Zahler M, Rinder H, Schein E, Gothe R (2000a) Detection of a new pathogenic Babesia microti-like species in dogs. Vet Parasitol 89(3):241-248

Zahler M, Rinder H, Zweygarth E, Fukata T, Maede Y, Schein E, Gothe R (2000b) 'Babesia gibsoni' of dogs from North America and Asia belong to different species. Parasitology 120(4):365-369 